This item was submitted to Loughborough's Research Repository by the author.

Items in Figshare are protected by copyright, with all rights reserved, unless otherwise indicated.

\title{
A reexamination of real stock returns, real interest rates, real activity, and inflation: Evidence from a large data set
}

PLEASE CITE THE PUBLISHED VERSION

https://doi.org//10.1111/fire.12137

\section{PUBLISHER}

(c) The Eastern Finance Association. Published by Wiley.

\section{VERSION}

AM (Accepted Manuscript)

\section{PUBLISHER STATEMENT}

This work is made available according to the conditions of the Creative Commons Attribution-NonCommercialNoDerivatives 4.0 International (CC BY-NC-ND 4.0) licence. Full details of this licence are available at: https://creativecommons.org/licenses/by-nc-nd/4.0/

\section{LICENCE}

CC BY-NC-ND 4.0

\section{REPOSITORY RECORD}

Jones, Paul M., Eric Olson, and Mark E. Wohar. 2019. "A Reexamination of Real Stock Returns, Real Interest Rates, Real Activity, and Inflation: Evidence from a Large Data Set”. figshare. https://hdl.handle.net/2134/26060. 


\title{
A Reexamination of Real Stock Returns, Real Interest Rates, \\ Real Activity, and Inflation: Evidence from a Large Dataset
}

\author{
Paul M. Jones \\ Pepperdine University \\ 24255 Pacific Coast Highway \\ paul.jones@pepperdine.edu \\ Malibu, CA 90263 \\ *Eric Olson \\ College of Business and Economics \\ West Virginia University \\ eric.olson@mail.wvu.edu \\ Morgantown, WV 26506 \\ Mark E. Wohar \\ College of Business \\ University of Nebraska-Omaha \\ And \\ Loughborough University UK \\ mwohar@mail.unomaha.edu \\ Omaha, NE 68182
}

November 16, 2016

\begin{abstract}
Using the informational sufficiency procedure from Forni and Gambetti (2014) along with data from McCracken and Ng (2014), we update the results of Lee (1992) and find that his Vector Autoregression (VAR) is informationally deficient. To correct this problem, we estimate a Factor Augmented VAR (FAVAR) and analyze the differences once informational deficiency is corrected with an emphasis on the relationship between real stock returns and inflation. In particular, we examine Modigliani and Cohn’s (1979) inflation illusion hypothesis, Fama's (1983) proxy hypothesis, and the "anticipated policy hypothesis.”
\end{abstract}

Key words: Informational Sufficiency, FAVAR, Stock Returns.

* Corresponding Author 


\section{Introduction}

The emergence of large datasets over the past decade has allowed researchers to incorporate more information in empirical analysis than ever before. Many relationships reported in previous studies could potentially be misleading or incorrect if relevant information is missing. Structural Vector Autoregressions (SVARs) have been standard for econometric analysis ever since first being introduced in Sims (1980). However, a crucial assumption in any SVAR model is that all relevant information (i.e. a sufficient number of variables) is accounted for within the VAR. Hansen and Sargent (1991), Lippi and Reichlin (1993), (1994), and Chari et al. (2008) show that if all relevant information is not included, the VAR can lead to incorrect conclusions. To test whether all relevant information is included in a VAR, Forni and Gambetti (2014) propose an informational sufficiency test along with a way to correct for a deficient VAR.

One relationship that has been explored extensively using SVARs is the relationship between real economic activity, inflation, and real stock returns. Originally, Fama (1981, 1983), based on a money demand model, suggested a negative association between inflation and real economic activity in conjunction with a positive association between stock returns and real economic activity leads to a spurious negative relationship between stock returns and inflation. Subsequently, many empirical studies have suggested that the observed negative stock returninflation relation is not a direct causal relation but rather reflects other fundamental relationships in the economy (Lee 1992). Another strand of literature suggests that the stock return-inflation relationship depends on whether the source of inflation is derived from supply or demand factors (Geske and Roll, 1983; Danthine and Donaldson, 1986; Lee, 1989). The negative relationship between asset returns and inflation may exist due to the source of inflation being related to 
nonmonetary factors such as real output shocks (Danthine and Donaldson, 1986; Stulz, 1986; Marshall, 1992; Bakshi and Chen, 1996).

Hess and Lee (1999) build upon the SVAR approach in Lee (1992) and use a SVAR model to identify aggregate demand and supply shocks that drive the stock return-inflation relation. Aggregate demand shocks drive a positive relationship between asset returns and inflation while aggregate supply shocks primarily result in a negative relationship. Hess and Lee (1999) report that aggregate demand shocks dominate in the pre-war period whereas aggregate supply shocks dominate in the post-war period. Lee (2010), using a SVAR, extends the Hess and Lee (1999) two regime framework to demonstrate that the Modiglinani and Cohn (1979) inflation illusion hypothesis is not compatible with pre-war data.

The primary aim of this paper is to update Lee's (1992) seminal paper which was one of the first to use a SVAR to examine the relationship between inflation and asset returns. Using the informational sufficiency procedure of Forni and Gambetti (2014) along with data from McCracken and Ng (2014), we update the results of Lee (1992) using generalized impulse responses and generalized variance decompositions to demonstrate the importance of controlling for macroeconomic factors in a VAR.

The central problem in VAR analysis is that the number of estimated parameters in a VAR expands quickly when additional variables are included. This often leads to only a subset of relevant variables being used in the analysis. As Forni and Gambetti (2014, page 124) point out, "The basic problem is that, while agents typically have access to rich information, VAR techniques allow a limited number of variables to be handled. If the econometrician's information set does not span that of the agents, the structural shocks are non-fundamental and cannot be obtained from a VAR.” 
Fortunately, the emergence of large data sets such as the one organized by McCracken and Ng (2014) and Factor Augmented VARs provide the framework for uncovering true causal relationships between variables. The procedure in Forni and Gambetti (2014) involves estimating the principal components of a large data set containing all available macroeconomic information and testing whether the estimated principal components Granger cause the other variables in the VAR. If the principal components Granger cause the other variables, the original VAR is deemed insufficient without the principal components in the VAR. In order to implement this procedure the econometrician first needs a large dataset. For our analysis we use the dataset created by McCracken and Ng (2014).

McCracken and Ng (2014) develop a large, monthly dataset that has several appealing features. The dataset can be updated in real-time using the FRED database, and the dataset is publicly available allowing for simpler replication of empirical analysis. McCracken and Ng’s (2014) dataset is perfectly suited for our analysis since Lee (1992) uses monthly data to determine causal relationships between asset returns, real activity, interest rates, and inflation. By combining the dataset in McCracken and Ng (2014) with the methodology in Forni and Gambetti (2014), we replicate Lee’s (1992) seminal Journal of Finance article and update the conclusions once we control for the omitted macroeconomic factors. In addition, we examine three of the most popular hypotheses to explain the negative real stock return-inflation relationship. Our results do not provide plausible evidence for Modigliani and Cohn’s (1979) inflation illusion hypothesis or Fama's (1983) proxy hypothesis. Instead, we find evidence for the "anticipated policy hypothesis” of Park and Ratti (2000) which is a variant of Geske and Roll (1983).

The rest of the paper proceeds as follows. In Section 2, we estimate the Lee (1992) model over a new sample period, 1960 to 2014. Section 3 looks at the tests for informational sufficiency 
and explains our methodology using the Forni and Gambetti (2014) testing procedure with the McCracken and Ng (2014) dataset. The following section — Section 4 — lays out the procedure for producing generalized impulse responses and variance decompositions. Section 5 shows our results. Due to the fact that our results do not support either the inflation illusion hypothesis or the proxy hypothesis, we estimate an additional FAVAR in Section 6. Section 7 concludes.

\section{Lee’s (1992) Model}

We use the model of Lee (1992) as our baseline. However, because the McCracken and Ng (2014) monthly dataset begins in 1960, we estimate Lee’s (1992) model over the 1960 2014 time period. Thus, while some comparisons to Lee (1992) will be made, our primary comparison will be between an estimated SVAR with principal components and one without principal components. $^{1}$

To begin, we obtain data from the Federal Reserve Economic Data (FRED) database. All variables are defined as in Lee (1992). ${ }^{2}$ In order to calculate real stock returns and real interest rates, we follow Lee (1992) and estimate the one-step-ahead forecast of inflation based upon the following four variable VAR:

$$
Z_{t}^{\prime}=\sum_{i=1}^{p} \Phi_{i, t} Z_{t-1}^{\prime}+\varepsilon_{t}
$$

\footnotetext{
${ }^{1}$ Furthermore, we do not provide a direct comparison of the results from Lee (1992) since our methodology is different from the original Lee (1992) paper. For example, Lee (1992) bases the ordering of the variables in the VAR on the results of the variance decompositions. Once we add the factors and use a new methodology for producing variance decompositions, the variance decompositions show very little explanatory power between the four variables. Thus, the reasoning behind selecting the ordering falls apart. For this reason, we decided to produce generalized impulse responses. The largest changes resulted from the inclusion of the factors in the FAVAR, so we decided to simplify the paper by removing some of the redundancies and only including the results over the same time period with and without the factors. The different baseline comparisons can be obtained upon request of the authors.

${ }^{2}$ Whereas Lee (1992) uses the one-month T-Bill rate, we use the three-month T-Bill rate due to its data availability.
} 
where $Z_{t}^{\prime}=\left[\mathrm{SR}_{t}, \mathrm{IR}_{t}, \mathrm{IPG}_{t}, \mathrm{INF}_{t}\right]$. SR and IR are nominal stock returns and nominal interest rates while IPG and INF are the growth rate of industrial production and the rate of inflation.

In order to generate the one step ahead forecast, we estimate (1) using the Kalman filter so that the coefficients in the matrix $\Phi_{i, t}$ are allowed to update as our data window expands. Put another way, the "states" in our SVAR will be the coefficients which will be updated sequentially as the dataset expands so that the coefficients in (1) are allowed to vary with time. As such, the measurement equations will be

$$
Z_{t}^{\prime}=\sum_{i=1}^{p} \Phi_{i, t} Z_{t-1}^{\prime}+\varepsilon_{t}
$$

where the state vectors follow a random walk:

$$
\Phi_{i, t}=\Phi_{i, t-1}+v_{t}
$$

where $\varepsilon_{t}$ and $v_{t}$ are independent.

As in Lee (1992), we subsequently subtract the inflation forecast from the nominal stock returns and nominal interest rates to obtain the real variables and estimate the following model:

$$
Z_{t}=\sum_{i=1}^{p} \Phi_{i} Z_{t-1}+\varepsilon_{t}
$$

such that $Z_{t}^{\prime}=\left[\mathrm{RSE}_{t}, \mathrm{RINT}_{t}, \mathrm{IPG}_{t}, \mathrm{INF}_{t}\right]$ where RSE, RINT, IPG, and INF are real stock returns, real real interest rates, the growth rate of industrial production, and the rate of inflation, respectively. $\varepsilon_{t} \sim(0, \Sigma)$ is a vector of independent and identically distributed error terms.

\section{Informational Sufficiency and FAVAR Methodology}

To begin Section 3, consider the four variable VAR from Lee (1992) over the 1960 2014 time period shown in equation (4). In order to test for informational sufficiency in (4), we need to obtain a set of principal components from a sufficiently large macroeconomic data set, 
$X_{t}^{*}$. As such, we obtain 129 monthly macroeconomic and financial time series from McCracken and $\mathrm{Ng}(2014)^{3}$. Rather than arbitrarily setting the number of factors in the dataset, we use the Bai and $\mathrm{Ng}$ (2002) criterion to determine the number of factors in the dataset. In utilizing the Bai and Ng (2002) criterion, we allow for a maximum of 10 factors. The PCP1, PCP2, ICP1, and ICP2 criterion all suggest seven factors. ${ }^{4}$

We follow McCracken and $\mathrm{Ng}$ (2014) and regress the $i$-th series in the dataset on the set of $r$ orthogonal factors in order to reveal information about each factor. ${ }^{5}$ As such, for each series in our data set we obtain an R-squared value that displays how much of the variation is explained by the estimated factors. That is, for $k=1, \ldots, 7$, this produces $R_{i}^{2}(k)$ for each series $i$. Thus, the marginal explanatory power of each factor $k$ is $m R_{i}^{2}(k)^{2}=R_{i}^{2}(k)-R_{i}^{2}(k-1)$ with $k=$ $2, \ldots, 7$. The factors explain 0.5 or more of the variation in 48 of the 129 series, and between 0.25 and 0.50 of 26 of the 129 series.

Table 1 displays the 5 series with the highest $m R_{i}^{2}(k)$ for each factor $k$. Not surprisingly, we find very similar results to those in McCracken and Ng (2014). As displayed in Table 1, the series with the highest marginal R-squared from the first factor $m R_{i}^{2}(1)$ are primarily real activity/output variables, so we interpret factor 1 as a real economic activity factor. Factor 2 is primarily governed by interest-rate spreads; thus, we follow McCracken and Ng (2014) and interpret factor 2 as a forward looking or expectations factor. Factor 3 is primarily an inflation factor given that most of the variables are price indices, and Factor 4 is primarily an interest rate

\footnotetext{
${ }^{3}$ We exclude six of the series to ensure we have a balanced panel: COGNO (Orders: Consumer Goods), ANDENOx (Orders: Nondefense Capital Goods), TWEXMMTH (Trade Weight U.S. FX Rate), UMCSENTx (Consumer Sentiment Index), HWI (Help Wanted Index for the U.S), and HWIURATIO (Help Wanted to Unemployed Ratio) ${ }^{4}$ The principal components are obtained using the @princomp procedure in the RATS software and are demeaned and standardized.

${ }^{5}$ We treated the factors as independent variables and add the factors sequentially to measure the changes in the Rsquared value.
} 
factor. Our results differ a bit from McCracken and Ng (2014) for Factors 5 and 6. Our results suggest that the explanatory power is primarily focused on a combination of unemployment, exchange rates, and monetary variables. Factor 7 is clearly an equity factor.

Next, we implement the procedure outlined in Forni and Gambetti (2014) to test whether Lee's (1992) model over the 1960 - 2014 time period is informationally sufficient. As noted in Forni and Gambetti (2014), a necessary requirement for innovation accounting is that the variables used within the VAR convey all the pertinent information. The testing procedure is comprised of the following three steps. First, obtain a large data set $X_{t}^{*}$ containing all relevant information. Second, set a maximum number of factors $P$ and compute the first $P$ principal components. Third, undertake a multivariate Granger causality test to see if the principal components Granger cause $Z_{t}^{*}$ — the variables of interest in the VAR. If the null hypothesis of no Granger causality is rejected, $Z_{t}^{*}$ (the VAR) is not sufficient, and Forni and Gambetti (2014) recommend estimating a FAVAR with the $P$ principal components added to the original VAR. If we fail to reject the null hypothesis, than the VAR is informationally sufficient. If informational sufficiency is rejected, including the factors in the VAR such that it becomes a FAVAR ensures that informational sufficiency is achieved.

Table 2 displays the Granger causality tests of the principal components on the variables in (4). We test for informational sufficiency as outlined above. As can be seen in Table 2, the principal components from $X_{t}^{*}$ Granger cause the variables in $Z_{t}^{*}$ indicating that the VAR is not informationally sufficient. Therefore, we follow Forni and Gambetti’s (2014) recommendation and add the principal components recursively and repeat the above procedure in order to determine if all the principal components are necessary. As can be seen in Table 2, informational sufficiency is rejected even after adding the components recursively into the system. Therefore, 
we augment the VAR to include the principal components so that $Z_{t}$ is now expanded to include the principal components:

$$
Y_{t}=\sum_{i=1}^{p} \Phi_{i} Y_{t-1}+u_{t}
$$

where $Y_{t}^{\prime}=\left[P C_{1}, P C_{2}, P C_{3}, P C_{4}, P C_{5}, P C_{6}, P C_{7}, \mathrm{RSE}_{t}, \mathrm{RINT}_{t}, \mathrm{IPG}_{t}, \mathrm{INF}_{t}\right]$ and $P C_{1}, P C_{2}, P C_{3}$, $P C_{4}, P C_{5}, P C_{6}, P C_{7}$ are the principal components. Given the uncertainty regarding the proper ordering of the variables in (5), we choose to undertake generalized impulse responses and generalized variance decompositions.

\section{Generalized Impulse Responses and Variance Decompositions}

Two econometric tools that were not available to Lee (1992) that are available today are the generalized impulse responses of Koop, Pesaran, and Potter (1996) and the generalized variance decompositions of Diebold and Yilmaz (2012). ${ }^{6}$ Diebold and Yilmaz (2012) define the own variance shares as the fraction of the H-step-ahead error variances in forecasting $z_{i}$ that are due to shocks to $\mathrm{z}_{i}$ for $i=1,2, \ldots \ldots, N$ and cross variance shares as the fraction of the H-stepahead error variances in forecasting $z_{i}$ that are due to shocks to $z_{i j}$ for $i, j=1,2, \ldots \ldots, N$ such that $i \neq j$.

The H-step-ahead forecast error variance decompositions are

$$
\theta_{i j}^{g}(H)=\frac{\sigma_{j j}^{-1} \sum_{h=0}^{H-1}\left(e_{i}^{\prime} A_{h} \sum e_{j}\right)^{2}}{\sum_{h=0}^{H-1}\left(e_{i}^{\prime} A_{h} \sum e_{i}\right)}
$$

where $\sum$ is the variance matrix for the error vector $\varepsilon, \sigma_{j j}$ is the standard deviation of the error term for the $j$ th equation, $A_{h}$ is a symmetric coefficient matrix, and $e_{i}$ is the selection vector, with

\footnotetext{
${ }^{6}$ We opted to use generalized variance decompositions and impulse responses rather than the SVAR of Lee (1992) because of the causal uncertainty regarding the ordering of the variables. However, it should be noted that we tested the informational sufficiency of the Lee (1992) model assuming the SVAR and ordering of the variables in Lee (1992) with the result that his model was not informationally sufficient.
} 
one as the ith element and zeros otherwise. Because the sum of the elements in each row of the variance decomposition table need not equal one, Diebold and Yilmaz (2012) normalize each entry in the variance decomposition matrix by:

$$
\tilde{\theta}_{i j}^{g}(H)=\frac{\theta_{i j}^{g}(H)}{\sum_{j=1}^{N} \theta_{i j}^{g}(H)}
$$

such that by construction $\sum_{j=1}^{N} \theta_{i j}^{g}(H)=1$. Diebold and Yilmaz (2012) then use the volatility contributions from the above generalized variance decompositions to construct the total spillover index as:

$$
S^{g}(H)=\frac{\sum_{\substack{i, j=1 \\ i \neq j}}^{N} \tilde{\theta}_{i j}^{g}(H)}{N} * 100
$$

Thus, the total spillover index measures the contribution of volatility shocks across the variables in our VAR to the total forecast error variance. ${ }^{7}$

The directional volatility spillovers Diebold and Yilmaz (2012) subsequently layout provide a decomposition of the total spillovers to those coming from (or to) a particular variable. The volatility spillover by variable $i$ to all other variables $j$ is

$$
S_{i}^{g}(H)=\frac{\sum_{\substack{j=1 \\ j \neq i}}^{N} \tilde{\theta}_{i j}^{g}(H)}{N} * 100 .
$$

Similarly, the directional volatility spillovers transmitted by variable $i$ to all other variables $j$ is

$$
S_{i}^{g}(H)=\frac{\sum_{\substack{j=1 \\ j \neq i}}^{N} \tilde{\theta}_{j i}^{g}(H)}{N} * 100
$$

The net spillover from variable $i$ to all other variables $j$ is

$$
S_{i}^{g}(H)=S_{\cdot i}^{g}(H)-S_{i \cdot}^{g}(H)
$$

\footnotetext{
${ }^{7}$ However, we do not report the total volatility spillover index since that is not our primary concern.
} 
The net pairwise volatility spillovers, are defined as

$$
S_{i}^{g}(H)=\frac{\tilde{\theta}_{j i}^{g}(H)-\widetilde{\theta}_{i j}^{g}(H)}{N} * 100 .
$$

Given the uncertainty regarding the ordering of the variables for identification, generalized impulse responses and variance decompositions have the advantage of producing results that are invariant to the ordering of the variables because of the use of the historically observed distribution of the errors.

\section{Results}

Figures 1 - 4 display the cumulative generalized impulse responses from estimating Lee’s (1992) model over the new 1960 - 2014 time period. ${ }^{8}$ Panel A does not include the principal components while Panel B displays the impulse responses from the FAVAR for the same four variables. ${ }^{9}$ All of the impulse responses in the VAR and the FAVAR are standardized and accumulated to ease the comparison between the two models.

As can be seen in Figures 1 - 4, the results are substantially different after including the principal components. Note in Figure 1, that a one standard deviation positive shock in real stock returns has a statistically significant 0.1 standard deviation contemporaneous positive effect on real interest rates in Panel A and a positive cumulative effect of 0.25 standard deviations after twenty four months. However, in Panel B of Figure 1 when the principal components are included, a one standard deviation shock in real stock returns has a -0.1 standard deviation contemporaneous effect on real interest rates and a cumulative -0.15 standard deviation effect after twenty four months.

\footnotetext{
8 The scale for the $\mathrm{x}$-axis for all of the graphs is months and the standard errors are computed from Monte Carlo simulations.

${ }^{9}$ The lag length of two for the VARs was determined by minimizing the multivariate BIC. The results are similar using lag lengths anywhere between two and six.
} 
The results across the two models are different for output as well. In Panel A, a shock to real stock returns increases output by 0.125 standard deviations contemporaneously and ends up increasing output by 0.6 standard deviations twenty four months after the real stock return shock. In Panel B the results are much more muted. The real stock return shock does not have a contemporaneous statistically significant effect on output and after twenty four months the cumulative effect is 0.15 standard deviations. As such, our results do not support a large positive wealth effect of real stock returns on output. The results for the shock to real stock returns on inflation are also different. In Panel A, a positive shock to real stock returns does not have any statistically significant effect on inflation. However, in Panel B of Figure 1 the positive shock in real stock returns has a statistically significant -0.15 standard deviation effect on inflation and the effect is quite persistent over the twenty four months.

In Figure 2, the shocks to real interest rates have quite different effects in the two models. In Panel A, a shock to real interest rates has a positive, contemporaneous 0.10 standard deviation effect on real stock returns and remains positive for the next three months before converging to zero. In Panel B, a shock to real interest rates has no contemporaneous effects on real stock returns but has an increasingly negative effect over the subsequent twenty four months. The shocks to real interest rates are quite similar and persistent in both models. However, the results on output are different. Note that the positive shock to real interest rates has a contemporaneous positive 0.10 standard deviation effect on output in Panel A and the effect continues to increase until three months after the shock resulting in a cumulative statistically significant 0.5 standard deviation effect after twenty four months. However, in Panel B, there is no contemporaneous statistically significant effect on output but the cumulative effect on output after twenty four 
months is -0.5 standard deviations. The effect of the real interest rate shock on inflation is similar in Panels A and B.

Figure 3 displays the impulse responses of a shock to output, as measured by industrial production, on the four variables examined in Lee (1992). In Panel A, the shock to output has a statistically significant 0.075 standard deviation increase in real stock returns whereas in Panel B the effect is close to zero. Moreover, in Panel A, when the VAR is not informationally sufficient, the shock to output results in a cumulative 0.15 standard deviation increase in real stock returns whereas in Panel B the cumulative effect of the output shock on real stock returns is not statistically different from zero after twenty four months. Both the contemporaneous and the cumulative effects of the shock to output on real interest rates is similar in Panels A and B. However, note that the effects of the output shock on inflation are different in Panels A and B. Whereas the shock in output results in a statistically significant 0.10 standard deviation increase in the inflation rate in Panel A, we are not able to conclude that the output shock has statistically significant effects in Panel B. Moreover, the point estimate of the output shock on inflation in Panel B is roughly half of that in Panel A.

Figure 4 displays the generalized impulse responses of a shock to inflation on the variables in the system. As can be seen in Panel A, a shock to inflation has a positive statistically significant effect on real stock returns for the first two months and continues to be significant through month twenty four. However, in Panel B, the shock to inflation has a -0.15 standard deviation effect on real stock returns and continues to have a negative effect over the subsequent twenty four months resulting in a cumulative effect of -0.3 standard deviations. Additionally, note that in Panel A the shock to inflation results in a cumulative increase of 0.20 standard deviations in real interest rates, whereas in Panel B there is no statistically significant effect after 
twenty four months. Moreover in Panel A, the inflation shock results in a 0.20 statistically significant standard deviation increase in output after twenty four months, whereas in Panel B there is no statistically significant effect. In fact, the point estimate in Panel B from the inflation shock on output is negative rather than positive.

An interesting and important exercise to undertake at this point is to see whether shocks to the factors that correspond to our four variables of interest have similar results; e.g., do shocks to the output factor cause an increase in our output variable? Do the shocks to the factors produce similar results to shocks to our corresponding variables? Figures 5 and 6 provide the answers to these questions. This exercise is an important check on our results; i.e., one would expect a shock to the real interest rate factor would affect the real interest rate. Figure 5 Panel A shows the impulse responses to a shock to the equity factor. Recall using the marginal R-squared in Table 1, the equity factor best explains the return on the S\&P 500, followed by the return on the S\&P 500 industrials, the S\&P 500 dividend yield, the S\&P 500 price to earnings ratio, and total housing starts. The shock to the equity factor in Figure 5 leads to an increase in the real stock returns variable although in the contemporaneous period there is very little change. The other three variables react somewhat differently to the equity factor shock compared to the shock to real stock returns in Figure 1 Panel B. This is likely due to the fact that the equity factor incorporates additional information besides just purely real stock returns.

Figure 5 Panel B displays the impulse responses to a shock to the real interest rate factor. These results correspond very closely to the impulse responses from a shock to the real interest rate presented in Figure 2 Panel B-the real interest rate increases, real stock returns decrease, output decreases, and inflation increases. Figure 6 Panel A shows how the four variables respond to a shock to the real economic activity factor. The results are largely consistent with the results to 
a shock in our output variable presented in Figure 3 Panel B — output increases, the real interest rate increases, and inflation increases although it is not statistically significant after 24 months. The effect on real stock returns is different between the two shocks; real stock decrease in response to the shock to the real economic activity factor, but increase for a period of time in response to the output shock.

Our final responses from a shock to the inflation factor, shown in Figure 6 Panel B, confirm the main results from the shock to inflation shown in Figure 4 Panel B-real stock returns decrease, the real interest rate increases, output decreases, and inflation increases. Overall, Figures 5 and 6 provide strong evidence that our analysis in Figures 1 - 4 accurately captures the true relationships between real stock returns, real interest rates, output, and inflation. This can be seen in the response to each of the variables when the corresponding factors are shocked. The responses of all of our variables to shocks to the factors in Figures 5 and 6 is very similar to the results discussed in Figures $1-4$ with the possible exception of the shock to the equity factor. ${ }^{10}$ The next part of our analysis discusses the results from the generalized variance decompositions.

Table 3 displays the generalized variance decompositions with the principal components included. Note that the last row (entitled To Others) and the last column (entitled From Others) are summary columns that display the amount of variation that a particular variable explains in other variables (To Others), as well as, the amount of variation that the other variables explain (From Others). First, it should be noted that we expect the variance decompositions to be dramatically different due to the number of variables included in the FAVAR model versus the

\footnotetext{
${ }^{10}$ Figures of generalized impulse response for all variables and all factors can be obtained upon request of the authors.
} 
Lee (1992) model. The bolded cells are highlighted if a variable explains 5\% or more of the variation in a variable.

As can be seen in row 1 , the three variables that explain the most variation in real stock returns are the expectations factor (7.4\%), the interest rate factor $(10.6 \%)$, factor 5 (8.7\%), the equity factor (26.5\%), and real stock returns itself (37.5\%). Somewhat surprisingly, neither the real economic activity factor, the inflation factor, output (IPG), nor inflation explain much of the variation in real stock returns. As can be seen in row 2, the real activity factor explains $6.2 \%$ of the variation in real interest rates, with the expectations factor explaining almost $8.5 \%$ of the variation, factor 4 explaining 5.5\%, and real interest rates itself accounting for $48.7 \%$ of the variation. Not surprisingly, note in row 3, that the real economic activity factor explains $26.6 \%$ of the variation in industrial production, the expectations factor explains $13 \%$ of the variation in industrial production, factor 4 explains $13.1 \%$, factor 5 explains 8.3\%, and output explains $32.7 \%$ of its own variation. Interestingly, in row 4 , the inflation factor explains $39.7 \%$ of the variation of inflation, and inflation itself explains $52.1 \%$ of its own variation.

The most striking result is that out of the three main conclusions from Lee (1992), only one continues to hold once the principal components are included. The only conclusion which remains valid is that inflation explains little variation in real activity. The other conclusions no longer hold. Real stock returns no longer explain a large portion of real activity, and real interest rates no longer explain a substantial fraction of the variation in inflation.

\subsection{Discussion of Results and Relationship to Prior Literature}

It certainly should be pointed out that the econometric tools to test for informational sufficiency have only recently been developed. However, our results suggest that it is certainly 
worth revisiting previous studies that use VARs and SVARs to better understand the relationship between economic activity and real stock returns. ${ }^{11}$ We believe that our SVAR suggests the following key results after the inclusion of the principal components. First, real stock returns have a statistically negative effect on real interest rates, a small statistically positive effect on output, and a statistically negative effect on inflation. Second, shocks in real interest rates have a statistically negative effect on output, a statistically negative effect on real stock returns, but a positive statistically significant effect on inflation. Third, shocks to output do not have statistically significant effects on real stock returns but do have statistically positive effects on real interest rates. Finally, shocks to inflation only have a statistically significant effect on real stock returns and on inflation itself.

Many previous empirical studies have documented the negative relationship between inflation and real stock returns post WWII. ${ }^{12}$ While many hypotheses have been proposed to explain the relationship, two of the most widely researched have been Modigliani and Cohn’s (1979) inflation illusion hypothesis and Fama’s (1983) proxy hypothesis. Modigliani and Cohn’s (1979) inflation illusion hypothesis essentially states that stock market investors experience an inflation illusion so that as inflation rises, investors discount the expected future earnings (dividends) more because nominal interest rates are higher. As such, stock prices are undervalued when inflation is high and are overvalued when inflation is low. This results in the negative relationship between stock returns and inflation. Fama (1983), on the other hand, argues in the proxy hypothesis that the negative relationship between inflation and real stock returns is spurious and due to the fact that inflation is negatively related to output whereas real stock returns are positively related to output.

\footnotetext{
${ }^{11}$ For example, see Park and Ratti (2000), Lee (1992, 2003, 2010), and Campbell and Vuolteenaho (2004).

12 See Nelson and Schwert (1977), Fama and Schwert (1977), and Gultekin (1983).
} 
While our results do confirm the negative relationship between real stock returns and inflation, our results do not really provide support for either Modigliani and Cohn’s (1979) inflation illusion hypothesis or Fama’s (1983) proxy hypothesis. If the inflation illusion hypothesis were true, one would expect that inflation would explain a substantial portion of the variance decomposition of real stock returns but inflation and the inflation factor only explain $3 \%$ of the variation in real stock returns. However, it should be noted that Campbell and Vuolteenaho (2004) argue that inflation explains $80 \%$ of the variation in the mispricing of equities relative to bonds; that is, the inflation illusion hypothesis may be still be true but not explain a lot of the variation in real stock returns if mispricing does not exist. The proxy hypothesis on the other hand posits a negative relationship between output and inflation and a positive relationship between real stock returns and output. Examination of the shocks to output in Figure 3 Panel B do not suggest a statistically significant long-run effect on real stock returns — although the results are positive in months three through twelve-nor a statistically significant effect of output on inflation in the long-run; in fact, the point estimate is positive not negative. However, another possibility suggested by Brandt and Wang (2003) and Bakaert and Engstrom (2010) is that aggregate risk aversion varies in response to changes in the inflation rate. Under such a scenario, time periods of high inflation coincides with time periods of high risk aversion suggesting that the relationship is time-varying.

\subsection{Time-varying Model}

Campbell, Sunderam and Viceira (2009) argue that the effects of macroeconomic variables on real stock returns are likely time-varying. ${ }^{13}$ As such, in order to explore that possibility, we estimate a time-varying FAVAR using a rolling 300 month window. Our first

\footnotetext{
${ }^{13} \mathrm{We}$ are grateful to the referee for making the suggestion of a time-varying model.
} 
window spans the 1960 - 1986 time period. However, one complicating issue is that we have eleven variables in the FAVAR. This does not allow enough observations in each window to estimate an eleven variable SVAR. That being the case, we estimate the Lee (1992) VAR with the rolling window but add the 7 principal components (2 lags of each principal component) as exogenous variables in the time-varying VAR. Our thinking was that by including the principal components as exogenous variables in the time-varying VAR, the information contained in the principal components would still be present for every window in our time-varying estimation. For each rolling window, we standardize the responses as above and then accumulate the impulse responses for 12 months. We subsequently estimate the model 1000 times for each window to obtain two standard deviation confidence intervals. Figures 7 and 8 display the cumulated 12 month impulse responses for the original Lee (1992) variables.

Panel A of Figure 7 displays the time-varying impulse responses to a shock in real stock returns. As can be seen in Panel A of Figure 7, shocks to real stock returns have consistently had negative effects on real interest rates. From 1986 - 2000, the effect is relatively constant at -0.3 standard deviations. However, the negative effect begins to dissipate beginning in the early 2000s and is close to 0 from 2005 through 2007 but continues to be negative through 2014. Note that the effects of a real stock return shock on output are 0 until the year 2000 when the effect increases to 0.3 standard deviations. However, it should be noted that the effect is not statistically significant until 2006. The effects of real stock returns on inflation are consistently negative and the negative effect essentially doubles around 2009. The effects of a shock to real interest rates are shown in Panel B of Figure 7. Note that the effect of a shock to real interest rates has no statistically significant effects on the other variables in the system except for inflation beginning 
after the financial crisis. The effect increases from 0 standard deviations in 2008 to 0.3 standard deviations in 2014.

Figure 8 displays the time-varying responses to output shocks in Panel A and inflation shocks in Panel B. Note that shocks to output have a statistically significant positive effect on real stock returns of approximately 2 standard deviations from 1986 - 2000, this effect increases to 3 standard deviations and then gradually falls until an abrupt fall in 2008 when the effect decreases to 1 standard deviation. Somewhat surprisingly, shocks to output do not have a statistically significant effect on real interest rates or inflation rates throughout the time period. Shocks to inflation are shown in Panel B of Figure 8. Inflation shocks do not appear to have statistically significant effects on the other variables in the system except for a few brief periods of statistical significance. The results in Figures 7 and 8 should be interpreted cautiously due to the rolling window used as well as the choice to accumulate the responses for 12 months. However, we do believe they are informative. First, the examination of the results does indicate that the relationships between the variables in the VAR changed in 2000 during and after the dotcom bust as well as after the financial crisis in 2008.

\section{Monetary Policy FAVAR}

A third hypothesis that has seen a substantial amount of attention in the literature is called the "anticipated policy hypothesis." ${ }^{14}$ Under this hypothesis, higher inflation leads to expectations of tighter monetary policy and these expectations lead to a decline in the stock market. In order to examine this hypothesis we repeat the methodology outlined in Section 3. That is we first consider the following five variable VAR over the 1960 - 2014 time period:

\footnotetext{
${ }^{14}$ As described in Park and Ratti (2000) which builds upon Gesk and Roll (1983), James, Koreisha, and Partch (1985), Kaul (1987) and Patelis (1997) and Thorbecke (1997).
} 


$$
X_{t}=\sum_{i=1}^{p} \Phi_{i} X_{t-1}+e_{t}
$$

such that $X_{t}^{\prime}=\left[\mathrm{RSE}_{t}, \mathrm{RINT}_{t}, \mathrm{IPG}_{t}, \mathrm{FF}_{t}, \mathrm{INF}_{t}\right]$ where RSE, RINT, IPG, FF, and INF are real stock returns, real real interest rates, the growth rate of industrial production, the federal funds rate, and the rate of inflation. $e_{t} \sim(0, \Sigma)$ is again a vector of independent and identically distributed error terms. We repeat the Forni and Gambetti (2014) informational sufficiency tests, and Table 4 displays the results. As can be seen, the 5 variable VAR is not informationally sufficient. As such, we again add the factors recursively and repeat the sufficiency tests. Our results suggest that all the components should be included in the VAR to ensure informational sufficiency. Thus, we augment the VAR to include the principal components so that $X_{t}$ is now expanded to include the principal components:

$$
W_{t}=\sum_{i=1}^{p} \Phi_{i} W_{t-1}+u_{t}
$$

where $W_{t}^{\prime}=\left[P C_{1}, P C_{2}, P C_{3}, P C_{4}, P C_{5}, P C_{6}, P C_{7}, \mathrm{RSE}_{t}, \mathrm{RINT}_{t}, \mathrm{IPG}_{t}, \mathrm{FF}_{t}, \mathrm{INF}_{t}\right]$ and $P C_{1}, P C_{2}$, $P C_{3}, P C_{4}, P C_{5}, P C_{6}, P C_{7}$ are the principal components.

Figure 9 displays the standardized cumulative generalized impulse responses from estimating (14). Panel A displays the results from a shock to real stock returns. Panel B displays the shocks to the federal funds rate, and Panel $\mathrm{C}$ displays the shocks to inflation. The first thing to note, is that if one compares the shocks to RSE and inflation in Panels A and C in Figure 9 to those in Panel B of Figure 1 and Panel B of Figure 4, the results are very similar. We believe the similarity in the results strongly supports the recommendations and results of Forni and Gambetti (2014). In Panel A of Figure 9, a shock in real stock returns does not have a statistically significant effect on the federal funds rate after twenty four months. However, the point estimate is negative over the corresponding twenty four months. In Panel B of Figure 9, the shock in the federal funds rate has a statistically significant negative effect on real stock returns. While the 
contemporaneous effect is zero, beginning three months after the shock, the effect is negative and statistically significant, and after twenty four months real stock returns are 0.4 standard deviations lower. Note that the shock to the federal funds rate has a 0.2 statistically significant positive effect on inflation one month after the shock but dissipates towards zero and is not statistically significant twenty four months after the shock. In Panel C, the shock to inflation has a negative effect on real stock returns.

Given the lack of evidence for the inflation illusion hypothesis and the proxy hypothesis, we interpret our negative significant effects of the federal funds rate on real stock returns as only very weakly supporting the "anticipated policy hypothesis.” The fact that shocks to the federal funds rate have positive statistically significant effects on inflation for the first ten months after the shock could be interpreted as the Federal Reserve reacting to contemporaneous inflation but monetary policy affecting inflation with a lag. However, for robustness, we also estimated the Generalized Variance Decompositions for the FAVAR in (14) to examine how much of the variation in real stock returns is accounted for by the Federal Funds Rate. Table 5 displays our results. As above, note that the last row (entitled To Others) and the last column (entitled From Others) are summary columns that display the amount of variation that a particular variable explains in other variables (To Others), as well as, the amount of variation that the other variables explain (From Others). Note that the Federal funds rate explains very little of the variation in real stock returns (1\%); the interest rate factor does explain about $12 \%$ of the variation in real stock returns which may be a reason why the federal funds rate explains such a little amount. Nevertheless, the results from the impulse responses and generalized variance decompositions certainly do not provide conclusive evidence in favor of the anticipated policy hypothesis. 


\section{Conclusion}

A critical assumption in a VAR model is that the included variables are able to account for all relevant information. If all relevant information is not included, the VAR can lead to incorrect conclusions. To test whether all relevant information is included in a VAR, Forni and Gambetti (2014) propose an informational sufficiency test and a procedure to correct a deficient VAR. Using this procedure along with data from McCracken and Ng (2014), we update Lee's (1992) seminal Journal of Finance article and find substantially different results once we control for macroeconomic factors. We find that real stock returns have a negative effect on real interest rates, a small positive effect on output, and a negative effect on inflation. Shocks to real interest rates have a negative effect on output, a negative effect on real stock returns, but a positive effect on inflation. Shocks to output do not have statistically significant effects on real stock returns but have positive effects on real interest rates. Finally, shocks to inflation only have a statistically significant effect on real stock returns and on inflation itself.

Given the negative relationship observed between real stock returns and inflation we review our results considering Modigliani and Cohn’s (1979) inflation illusion hypothesis, Fama’s (1983) proxy hypothesis, and the “anticipated policy hypothesis” as possible explanations. However, we do not believe that our results provide concrete evidence for any of these hypotheses. Other explanations, such as Brandt and Wang's (2003) and Bakaert and Engstrom (2010) suggestion that risk aversion varies in response to inflation shocks may be plausible explanations of our results and provide a path for future research for FAVAR models exploring the relationship between real stock returns and macroeconomic variables. Finally, we believe our paper has significant implications for the macroeconomics-finance literature. Illustrating the differences between the shocks from a VAR that is not informationally sufficient 
with a FAVAR that is informationally sufficient illustrates the importance of using FAVARs to correctly identify macroeconomic-finance relationships. Ultimately, our paper provides a better understanding about the true relationships between stock returns, interest rates, real activity, and inflation while controlling for many macroeconomic factors. Using information in large datasets, such as McCracken and Ng (2014), can provide new insights into the relationships between macroeconomic variables and financial variables. 


\section{References}

Bai, J., and S. Ng. "Determining the number of factors in approximate factor models." Econometrica (2002), 70: 191-221.

Bakshi, G.S., and Z. Chen. "Inflation, asset prices, and the term structure of interest rates in monetary economies.” Review of Financial Studies (1) (1996), 241-276.

Bekaert, Geert, and Eric Engstrom. "Inflation and the stock market: Understanding the "Fed Model”." Journal of Monetary Economics 57, no. 3 (2010): 278-294.

Brandt, Michael W., and Kevin Q. Wang. "Time-varying risk aversion and unexpected inflation." Journal of Monetary Economics 50, no. 7 (2003): 1457-1498.

Campbell, John Y., Adi Sunderam, and Luis M. Viceira. "Inflation bets or deflation hedges? The changing risks of nominal bonds.” No. w14701. National Bureau of Economic Research, (2009).

Campbell, John Y., and Tuomo Vuolteenaho. Inflation illusion and stock prices. No. w10263. National bureau of economic research, 2004.

Chari, Varadarajan V., Patrick J. Kehoe, and Ellen R. McGrattan. "Are structural VARs with long-run restrictions useful in developing business cycle theory?." Journal of Monetary Economics 55, no. 8 (2008): 1337-1352.

Diebold, F.X., and K. Yilmaz. "Better to give than to receive: Predictive directional measurement of volatility spillovers.” International Journal of Forecasting (2012), 28: 57-66.

Danthine, J.P., and J. Donaldson. "Inflation and asset prices in an exchange economy”. Econometrica 54 (1986), 585-606.

Fama, E.F., "Stock returns, real activity, inflation and money.” American Economic Review 71, (1981): 545-565.

Fama, E.F., “Stock returns, real activity, inflation and money: Reply.” American Economic Review 73 (1983), 471-472.

Fama, E.F., and G.W. Schwert. “Asset returns and inflation.” Journal of Financial Economics (1977) 5: 115-146.

Forni, Mario, and Luca Gambetti. "Sufficient information in structural VARs."Journal of Monetary Economics 66 (2014): 124-136.

Geske, R., and R. Roll. “The monetary and fiscal linkage between stock returns and inflation.” Journal of Finance 38, 1-33 (1983). 
Gultekin, N.B. "Stock market returns and inflation: Evidence from other countries." Journal of Finance (1983), 38: 49-65.

Hansen, Lars Peter, and Thomas J. Sargent. "Two problems in interpreting vector autoregressions." In Hansen, Sargent (Eds.) Rational Expectations Econometrics (1991): 77-119.

Hess, P.J., and B.S. Lee. "Stock returns and inflation with supply and demand disturbances." Review of Financial Studies 12 (1999), 1203-1218.

Koop, Gary, M. Hashem Pesaran, and Simon M. Potter. "Impulse Response Analysis in Nonlinear Multivariate Models.” Journal of Econometrics (1996), 74: 119-147.

Lippi, Marco, and Lucrezia Reichlin. "The dynamic effects of aggregate demand and supply disturbances: Comment." The American Economic Review (1993): 644-652.

. "VAR analysis, nonfundamental representations, Blaschke matrices." Journal of Econometrics 63, no. 1 (1994): 307-325

Lee, B.S., "Solving, estimating and testing a nonlinear stochastic equilibrium model with an example of the asset returns and inflation relationship.” Journal of Economic Dynamics and Control 13 (1989), 499-531.

. "Causal relations among stock returns, interest rates, real activity, and inflation." The Journal of Finance 47, no. 4 (1992): 1591-1603.

. "Asset returns and inflation in response to supply, monetary, and fiscal

disturbances." Review of Quantitative Finance and Accounting 21, no. 3 (2003): 207-231.

. "Stock returns and inflation revisited: An evaluation of the inflation illusion hypothesis." Journal of Banking \& Finance 34, no. 6 (2010): 1257-1273.

Marshall, D.A., “Inflation and asset returns in a monetary economy.” Journal of Finance 47 (1992), 1315-1342.

McCracken, Michael, and Serena Ng. "FRED-MD: A Monthly Database for Macroeconomic Research." December, available at http://www. columbia. edu/sn2294/papers/freddata. pdf (2014).

Modigliani, F., and R. Cohn. "Inflation, rational valuation, and the market.” Financial Analysts Journal 35 (1979), 24-44.

Nelson, C.R. and G.W. Schwert. "Short-term interest rates as predictors of inflation: On testing the hypothesis that the real rate of interest is constant." American Economic Review (1977), 67: 478-486. 
Park, Kwangwoo, and Ronald A. Ratti. "Real activity, inflation, stock returns, and monetary policy." Financial Review 35, no. 2 (2000): 59-78.

Sims, Christopher A. "Macroeconomics and reality." Econometrica: Journal of the Econometric Society (1980): 1-48.

Stulz, R.M. “Asset pricing and expected inflation.” Journal of Finance (1986), 41: 209-223. 


\begin{tabular}{|c|c|c|c|c|c|}
\hline \multicolumn{6}{|c|}{ Table 1: Identification of Factors Using Marginal R-Squares $\left(m R_{i}(k)^{2}\right)$} \\
\hline$m R_{i}(1)^{2}$ & 0.26 & $m R_{i}(2)^{2}$ & 0.19 & $m R_{i}(3)^{2}$ & 0.36 \\
\hline $\begin{array}{l}\text { All Employees: } \\
\text { Goods-Producing }\end{array}$ & 0.75591 & $\begin{array}{l}5 \text { yr. - FFR } \\
\text { spread }\end{array}$ & 0.46127 & CPI: Commodities & 0.81672 \\
\hline $\begin{array}{l}\text { All Employees: } \\
\text { Manufacturing }\end{array}$ & 0.73388 & $\begin{array}{l}10 \text { yr. - FFR } \\
\text { spread }\end{array}$ & 0.4297 & $\begin{array}{l}\text { PCE: Nondurable } \\
\text { goods }\end{array}$ & 0.79797 \\
\hline $\begin{array}{l}\text { All Employees: } \\
\text { Durable goods }\end{array}$ & 0.67753 & $\begin{array}{l}1 \text { yr. - FFR } \\
\text { spread }\end{array}$ & 0.39259 & CPI inflation & 0.76672 \\
\hline IP: Manufacturing & 0.66929 & $\begin{array}{l}6 \text { Mo. - FFR } \\
\text { spread }\end{array}$ & 0.33531 & $\begin{array}{l}\text { CPI: All items less } \\
\text { medical care }\end{array}$ & 0.72492 \\
\hline $\begin{array}{l}\text { Capacity Utilization: } \\
\text { Manufacturing }\end{array}$ & 0.64892 & $\begin{array}{l}\text { Aaa - FFR } \\
\text { spread }\end{array}$ & 0.29401 & $\begin{array}{l}\text { CPI: All items less } \\
\text { shelter }\end{array}$ & 0.695 \\
\hline$m R_{i}(4)^{2}$ & 0.25 & $m R_{i}(5)^{2}$ & 0.05 & $m R_{i}(6)^{2}$ & 0.05 \\
\hline 1-Year T-bond & 0.50889 & $\begin{array}{l}\text { Retail and Food } \\
\text { Services Sales }\end{array}$ & $\begin{array}{r}0.086 \\
03 \\
\end{array}$ & $\begin{array}{l}\text { IP: Consumer } \\
\text { Goods }\end{array}$ & 0.14133 \\
\hline 5-Year T-bond & 0.50311 & Credit to PI ratio & $\begin{array}{r}0.046 \\
68\end{array}$ & $\begin{array}{l}\text { Ave. Hourly } \\
\text { Earnings: } \\
\text { Manufacturing }\end{array}$ & 0.04298 \\
\hline 10-Year T-bond & 0.46398 & $\begin{array}{l}\text { Average } \\
\text { Duration of } \\
\text { Unemployment }\end{array}$ & $\begin{array}{r}0.046 \\
\quad 27 \\
\end{array}$ & $\begin{array}{l}\text { Total Nonrevolving } \\
\text { Credit }\end{array}$ & 0.03456 \\
\hline 6-Month T-bill & 0.44706 & $\begin{array}{l}\text { Japan / U.S. FX } \\
\text { Rate }\end{array}$ & $\begin{array}{r}0.045 \\
1\end{array}$ & $\begin{array}{l}\text { St. Louis Adjusted } \\
\text { Monetary Base }\end{array}$ & 0.03223 \\
\hline $\begin{array}{l}\text { Aaa Corporate Bond } \\
\text { Yield }\end{array}$ & 0.42458 & $\begin{array}{l}\text { Ave. Hourly } \\
\text { Earnings: } \\
\text { Construction }\end{array}$ & $\begin{array}{r}0.028 \\
73\end{array}$ & $\begin{array}{l}\text { Ave. Hourly } \\
\text { Earnings: } \\
\text { Manufacturing }\end{array}$ & 0.01391 \\
\hline$m R_{i}(7)^{2}$ & 0.15 & & & & \\
\hline $\begin{array}{l}\text { Return on the S\&P } \\
500\end{array}$ & 0.4717 & & & & \\
\hline S\&P: Industrials & 0.4638 & & & & \\
\hline S\&P div yield & 0.40026 & & & & \\
\hline $\begin{array}{l}\text { S\&P: Price-Earnings } \\
\text { Ratio }\end{array}$ & 0.36816 & & & & \\
\hline Starts: Total & 0.15437 & & & & \\
\hline
\end{tabular}




\begin{tabular}{|c|c|c|}
\hline & $\begin{array}{c}\text { Principle Components Included in the } \\
\text { Sufficiency Test }\end{array}$ & $\begin{array}{c}\text { Sufficiency Test } \\
\text { F-Statistic }\end{array}$ \\
\hline $\begin{array}{l}\text { Sufficiency } \\
\text { Test } 1\end{array}$ & All & $\begin{array}{c}805.66 * * * \\
(0.00)\end{array}$ \\
\hline $\begin{array}{l}\text { Sufficiency } \\
\text { Test } 2\end{array}$ & PC1 & $\begin{array}{l}808.42^{* * *} \\
(0.00)\end{array}$ \\
\hline $\begin{array}{l}\text { Sufficiency } \\
\text { Test } 3\end{array}$ & PC1, PC2 & $\begin{array}{l}823.47 * * * \\
(0.00)\end{array}$ \\
\hline $\begin{array}{l}\text { Sufficiency } \\
\text { Test } 4\end{array}$ & PC1, PC2, PC3 & $\begin{array}{c}784.23 * * * \\
(0.00)\end{array}$ \\
\hline $\begin{array}{l}\text { Sufficiency } \\
\text { Test } 5\end{array}$ & PC1, PC2, PC3,PC4 & $\begin{array}{l}670.54 * * * \\
(0.00)\end{array}$ \\
\hline $\begin{array}{l}\text { Sufficiency } \\
\text { Test } 6\end{array}$ & PC1, PC2, PC3,PC4,PC5 & $\begin{array}{l}639.79 * * * \\
(0.00)\end{array}$ \\
\hline $\begin{array}{l}\text { Sufficiency } \\
\text { Test } 7\end{array}$ & PC1, PC2, PC3,PC4,PC5, PC6 & $\begin{array}{c}436.14 * * * \\
(0.00)\end{array}$ \\
\hline
\end{tabular}

Notes: The null hypothesis for each test is that there is no granger causality. If we cannot reject the null hypothesis, the VAR is informationally sufficient. If the null hypothesis is rejected, the VAR is not informationally sufficient and the VAR must be estimated with the principal components. Each Prob-value is given in parenthesis. * represents significance at the $10 \%$ level; ** represents significance at the $5 \%$ level; *** represents significance at the $1 \%$ level. 


\section{Table 3: FAVAR (Equation 5) Generalized Variance Decompositions}

\begin{tabular}{|c|c|c|c|c|c|c|c|c|c|c|c|c|}
\hline \multirow{2}{*}{$\begin{array}{l}\text { Variables } \\
\text { Explained }\end{array}$} & \multicolumn{12}{|c|}{ By Innovations in } \\
\hline & $\begin{array}{c}\text { Real } \\
\text { Activity } \\
\text { Factor }\end{array}$ & $\begin{array}{l}\text { Expect. } \\
\text { Factor }\end{array}$ & $\begin{array}{c}\text { INF } \\
\text { Factor }\end{array}$ & $\begin{array}{c}\text { Interest } \\
\text { Rate } \\
\text { Factor }\end{array}$ & Factor 5 & Factor 6 & $\begin{array}{l}\text { Equity } \\
\text { Factor }\end{array}$ & RSE & RINT & IPG & INF & $\begin{array}{l}\text { From } \\
\text { Others }\end{array}$ \\
\hline RSE & 1.3 & 7.4 & 2 & 10.6 & 1 & 8.7 & 26.5 & 37.5 & 2.4 & 1.5 & 1.1 & 63 \\
\hline RINT & 6.2 & 8.5 & 0.8 & 22 & 5.5 & 4.1 & 1.4 & 0.7 & 48.7 & 1.7 & 0.5 & 51 \\
\hline IPG & 26.6 & 13.1 & 0.5 & 2.8 & 13.1 & 8.3 & 0.7 & 0.4 & 1.4 & 32.7 & 0.3 & 67 \\
\hline INF & 0.2 & 0.2 & 39.7 & 0.8 & 0.2 & 2.1 & 3.1 & 0.8 & 0.4 & 0.3 & 52.1 & 48 \\
\hline To others & 81 & 79 & 49 & 57 & 48 & 32 & 44 & 8 & 57 & 72 & 50 & \\
\hline
\end{tabular}


Table 4: Forni and Gambetti (2014) Informational Sufficiency Tests (1960 - 2014) (Equation 14)

\begin{tabular}{l|c:c} 
& $\begin{array}{c}\text { Principle Components Included in the } \\
\text { Sufficiency Test }\end{array}$ & $\begin{array}{c}\text { Sufficiency Test } \\
\text { F-Statistic }\end{array}$ \\
\hline Sufficiency & All & $617.18^{* * *}$ \\
Test 1 & $(0.00)$ \\
\hline Sufficiency & PC1 & $694.38^{* * *}$ \\
Test 2 & $(0.00)$ \\
\hline Sufficiency & PC1, PC2 & $804.28^{* * *}$ \\
Test 3 & PC1, PC2, PC3 & $(0.00)$ \\
\hline Sufficiency & & $791.45^{* * *}$ \\
Test 4 & PC1, PC2, PC3,PC4 & $(0.00)$ \\
\hline Sufficiency & & $652.47^{* * *}$ \\
Test 5 & PC1, PC2, PC3,PC4,PC5 & $(0.00)$ \\
\hline Sufficiency & & $579.93^{* * *}$ \\
Test 6 & PC1, PC2, PC3,PC4,PC5, PC6 & $(0.00)$ \\
\hline Sufficiency & & $418.01^{* * *}$ \\
Test 7 & & $(0.00)$ \\
\hline
\end{tabular}

Notes: The null hypothesis for each test is that there is no granger causality. If we cannot reject the null hypothesis, the VAR is informationally sufficient. If the null hypothesis is rejected, the VAR is not informationally sufficient and the VAR must be estimated with the principal components. Each Prob-value is given in parenthesis. * represents significance at the $10 \%$ level; ** represents significance at the $5 \%$ level; *** represents significance at the $1 \%$ level. 
Table 5: FAVAR (Equation 14) Generalized Variance Decompositions

\begin{tabular}{|c|c|c|c|c|c|c|c|c|c|c|c|c|c|}
\hline \multirow{2}{*}{$\begin{array}{l}\text { Variables } \\
\text { Explained }\end{array}$} & \multicolumn{13}{|c|}{ By Innovations in } \\
\hline & $\begin{array}{c}\text { Real } \\
\text { Activity } \\
\text { Factor }\end{array}$ & $\begin{array}{l}\text { Expect. } \\
\text { Factor }\end{array}$ & $\begin{array}{c}\text { INF } \\
\text { Factor }\end{array}$ & $\begin{array}{c}\text { Interest } \\
\text { Rate } \\
\text { Factor }\end{array}$ & Factor 5 & Factor 6 & $\begin{array}{l}\text { Equity } \\
\text { Factor }\end{array}$ & RSE & RINT & IPG & FFR & INF & $\begin{array}{l}\text { From } \\
\text { Others }\end{array}$ \\
\hline RSE & 1.1 & 8.3 & 2.1 & 11.8 & 0.6 & 4.4 & 29.1 & 36.6 & 2.6 & 1.4 & 1 & 0.9 & 63 \\
\hline RINT & 4.8 & 5.5 & 0.5 & 16.4 & 5.4 & 3.4 & 1.8 & 0.3 & 44.5 & 1.2 & 15.8 & 0.3 & 55 \\
\hline IPG & 25.4 & 12.9 & 0.5 & 3.1 & 12.3 & 7.7 & 1.1 & 0.3 & 1.3 & 32.2 & 2.9 & 0.2 & 68 \\
\hline FFR & 4.9 & 11 & 0.2 & 4.9 & 5.8 & 2.9 & 3 & 0.1 & 18.3 & 1.3 & 47.5 & 0.1 & 52 \\
\hline INF & 0.2 & 0.3 & 36.7 & 2.2 & 0.1 & 1.6 & 3.4 & 0.6 & 0.5 & 0.3 & 2.3 & 51.9 & 48 \\
\hline To others & 77 & 85 & 46 & 58 & 48 & 26 & 50 & 6 & 68 & 65 & 72 & 48 & 649 \\
\hline
\end{tabular}

Note: Table 3 displays the generalized variance decompositions from estimating the FAVAR model. The column entitled From Others is simply the amount of total variation explained by the other

variables in the system excluding its own variation. The To Others row explains the amount of total variation that the column variable explains of the other variables in the system excluding itself. The other columns and rows display the generalized variance decompositions. 


\section{Figure 1: Generalized Impulse Responses of Variables to a Shock in Real Stock Returns}

Panel A: Lee’s (1992) Model using Generalized Impulse Responses without Principal Components included in the VAR
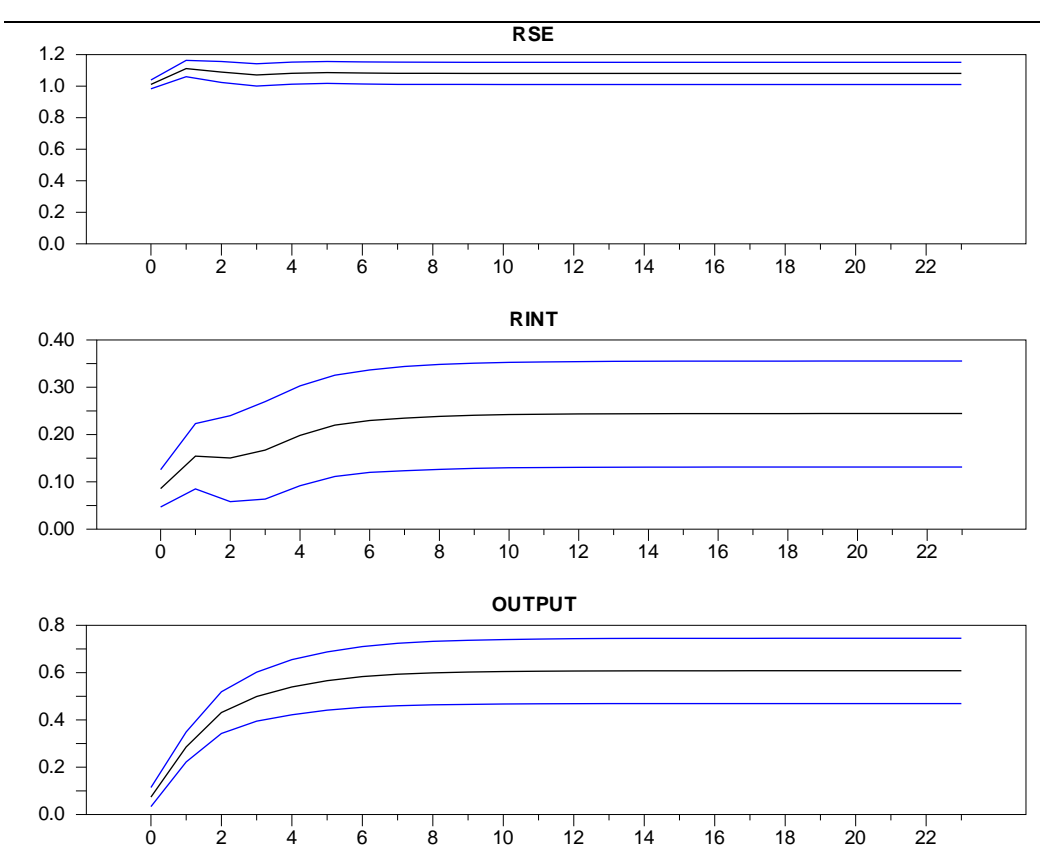

INF

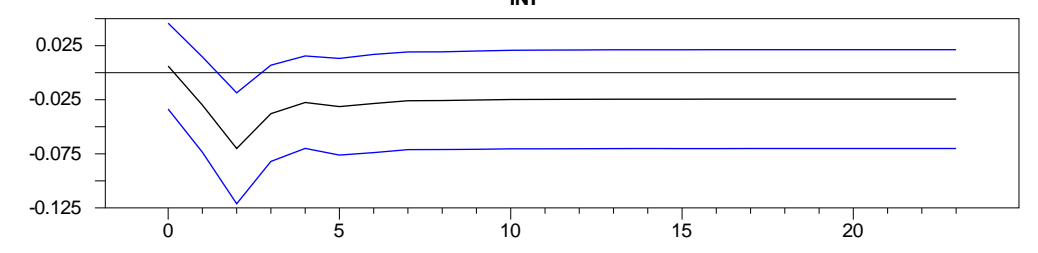

Panel B: FAVAR using Generalized Impulse Responses with Principal Components
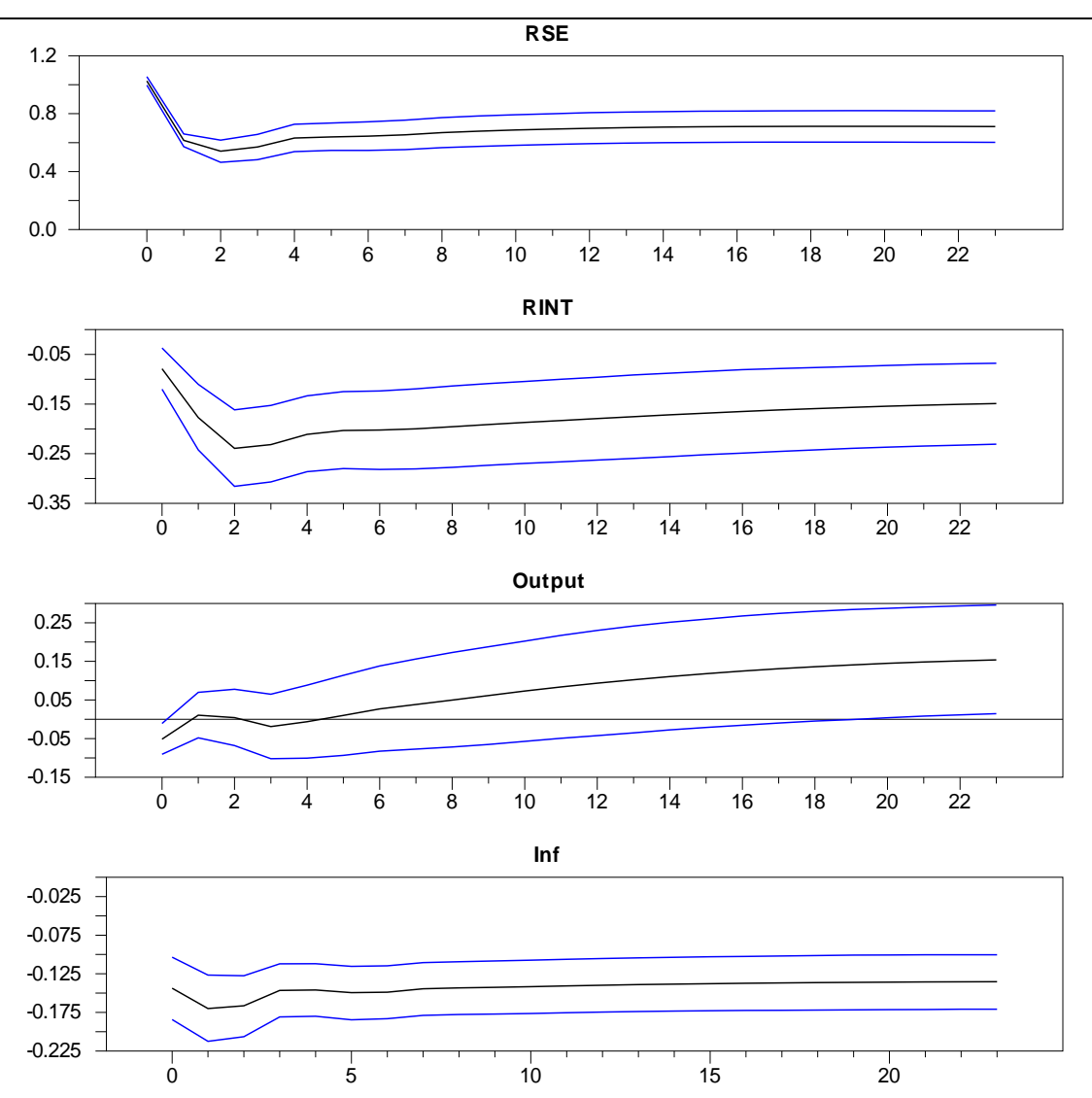


\section{Figure 2: Generalized Impulse Responses of Variables to a Shock in Real Interest Rates}

Panel A: Lee’s (1992) Model using Generalized Impulse Responses without Principal Components included in the VAR
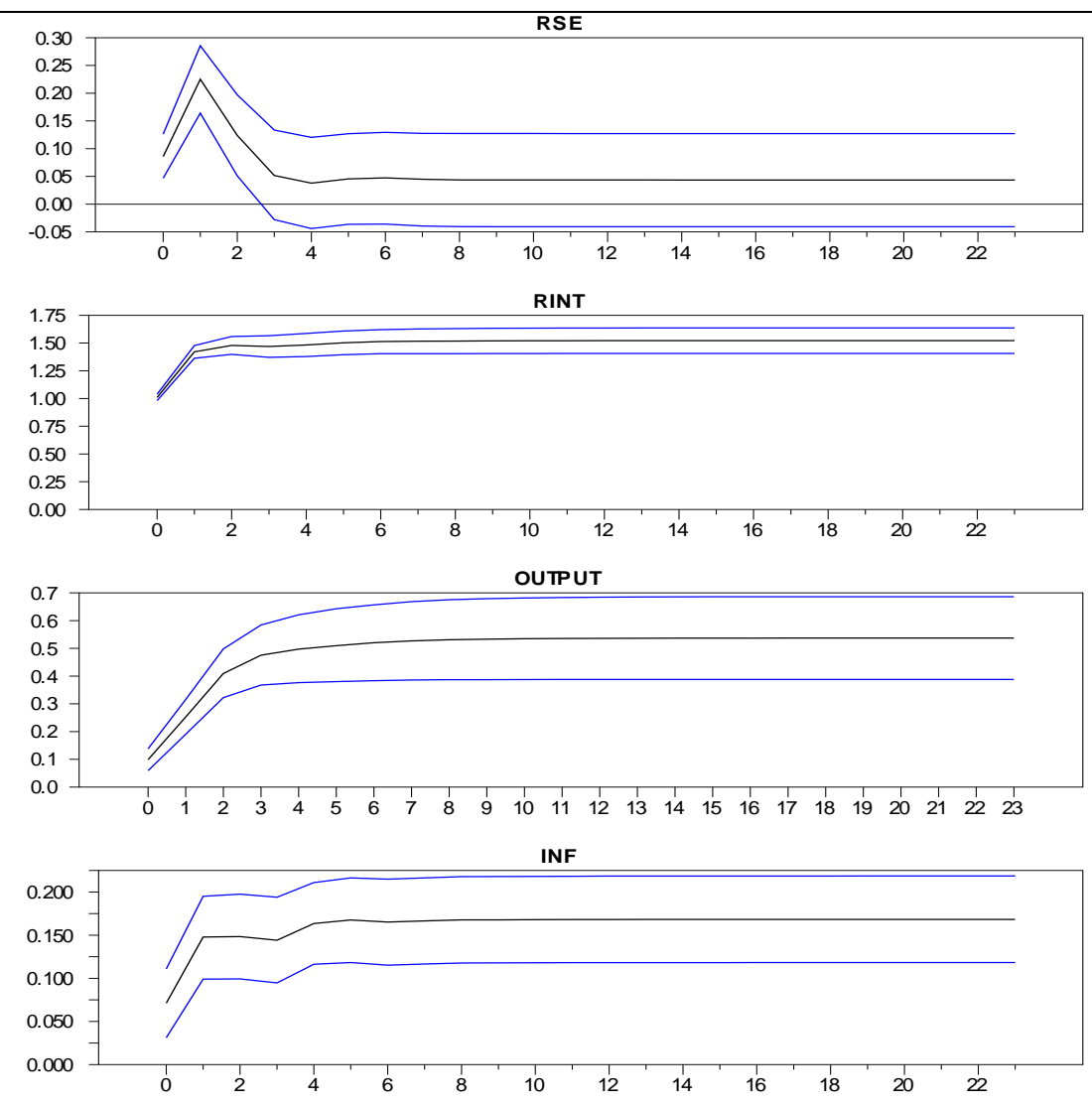

Panel B: FAVAR using Generalized Impulse Responses with Principal Components
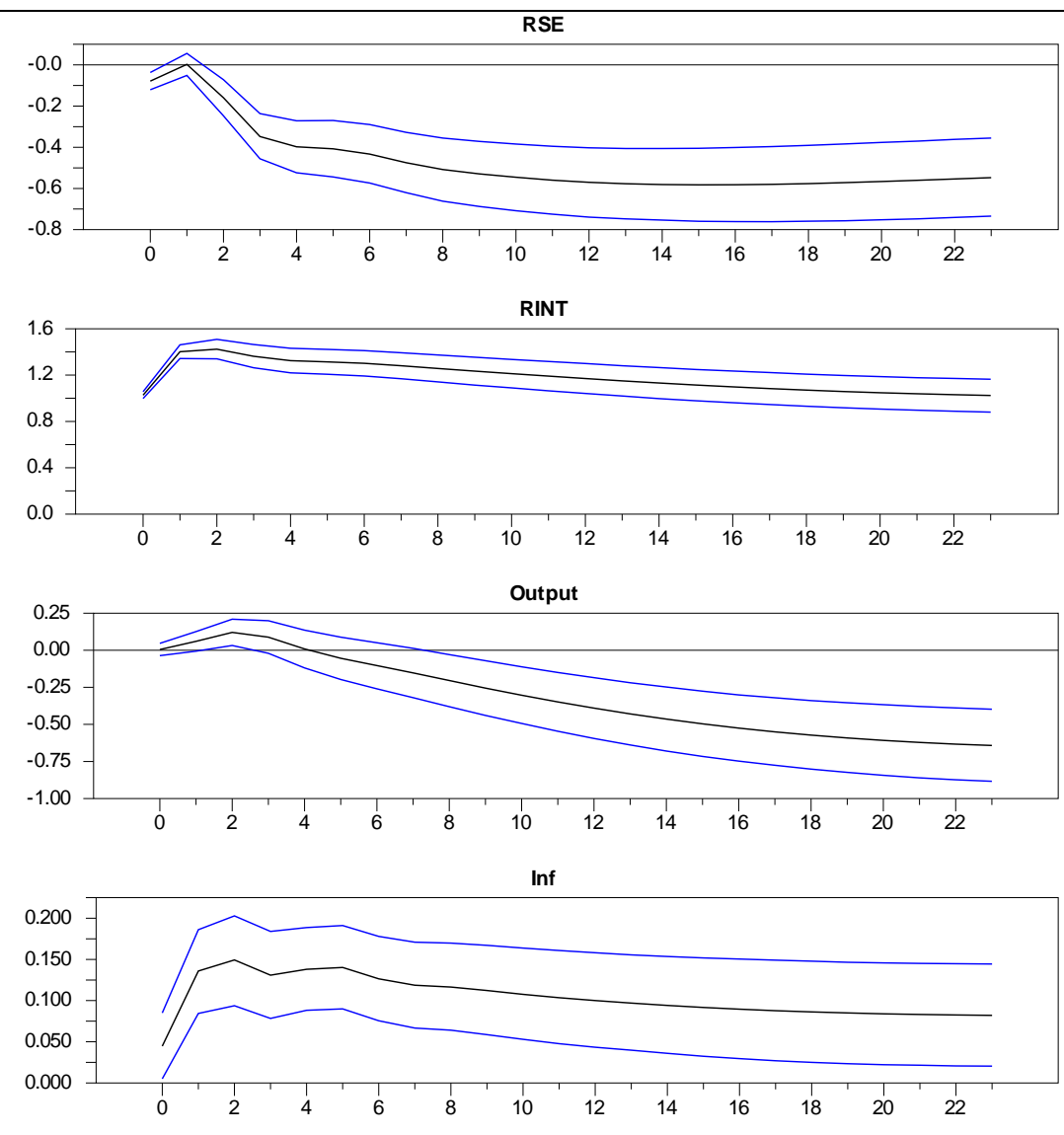


\section{Figure 3: Generalized Impulse Responses of Variables to a Shock in Output}

Panel A: Lee's (1992) Model using Generalized Impulse Responses without Principal Components included in the VAR
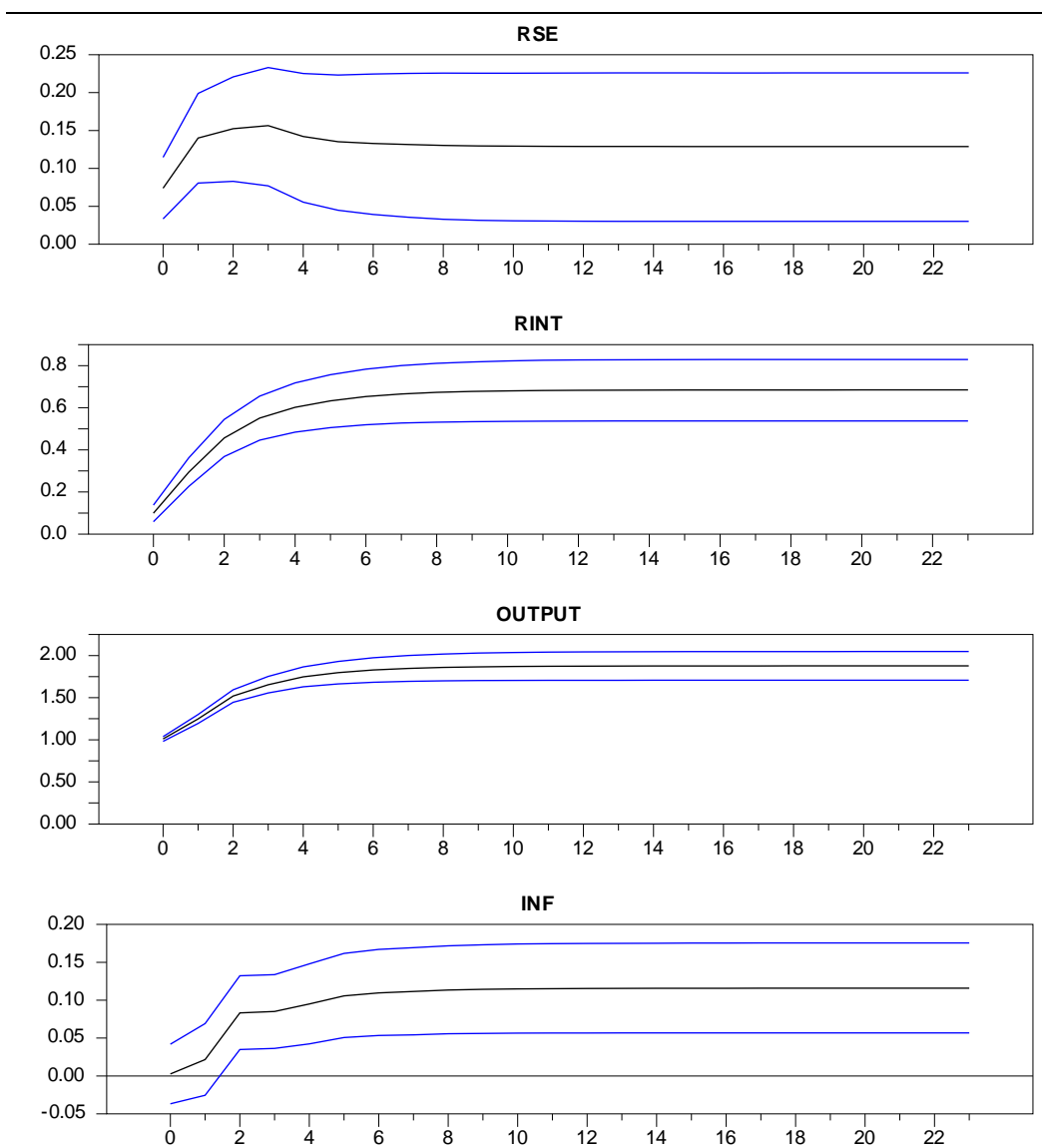

Panel B: FAVAR using Generalized Impulse Responses with Principal Components
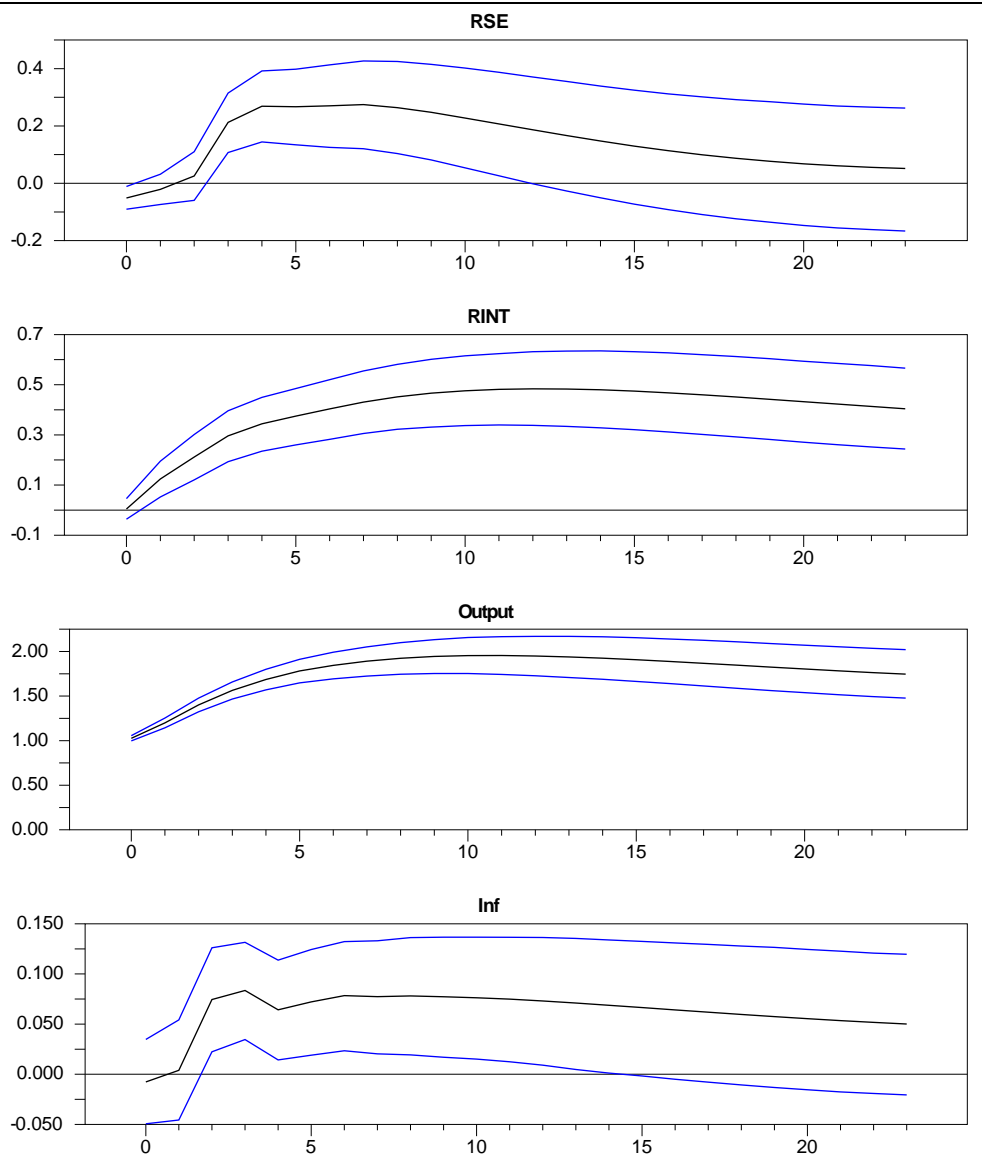


\section{Figure 4: Generalized Impulse Responses of Variables to a Shock in Inflation}

Panel A: Lee's (1992) Model using Generalized Impulse Responses without Principal Components included in the VAR
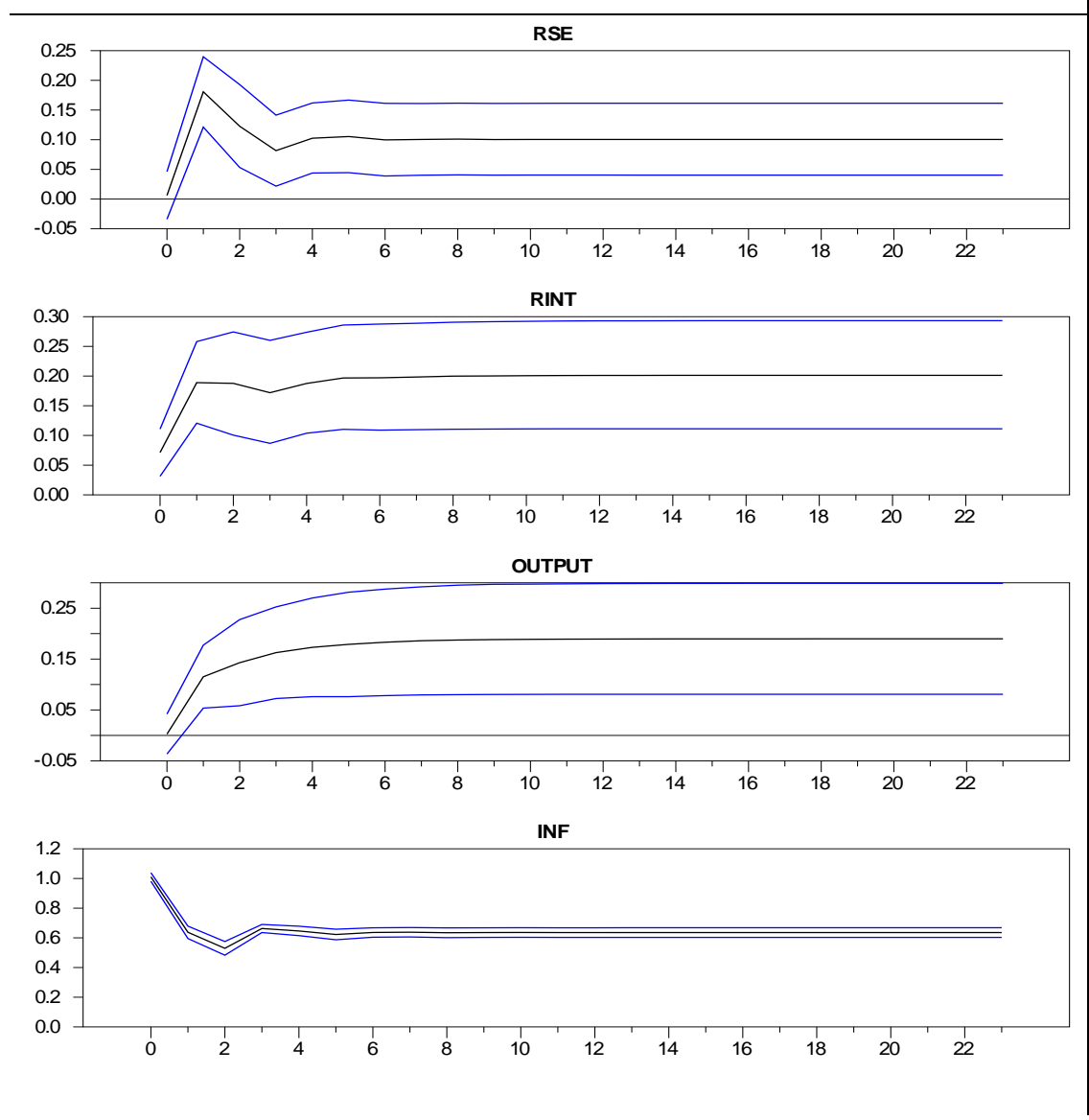

Panel B: FAVAR using Generalized Impulse Responses with Principal Components
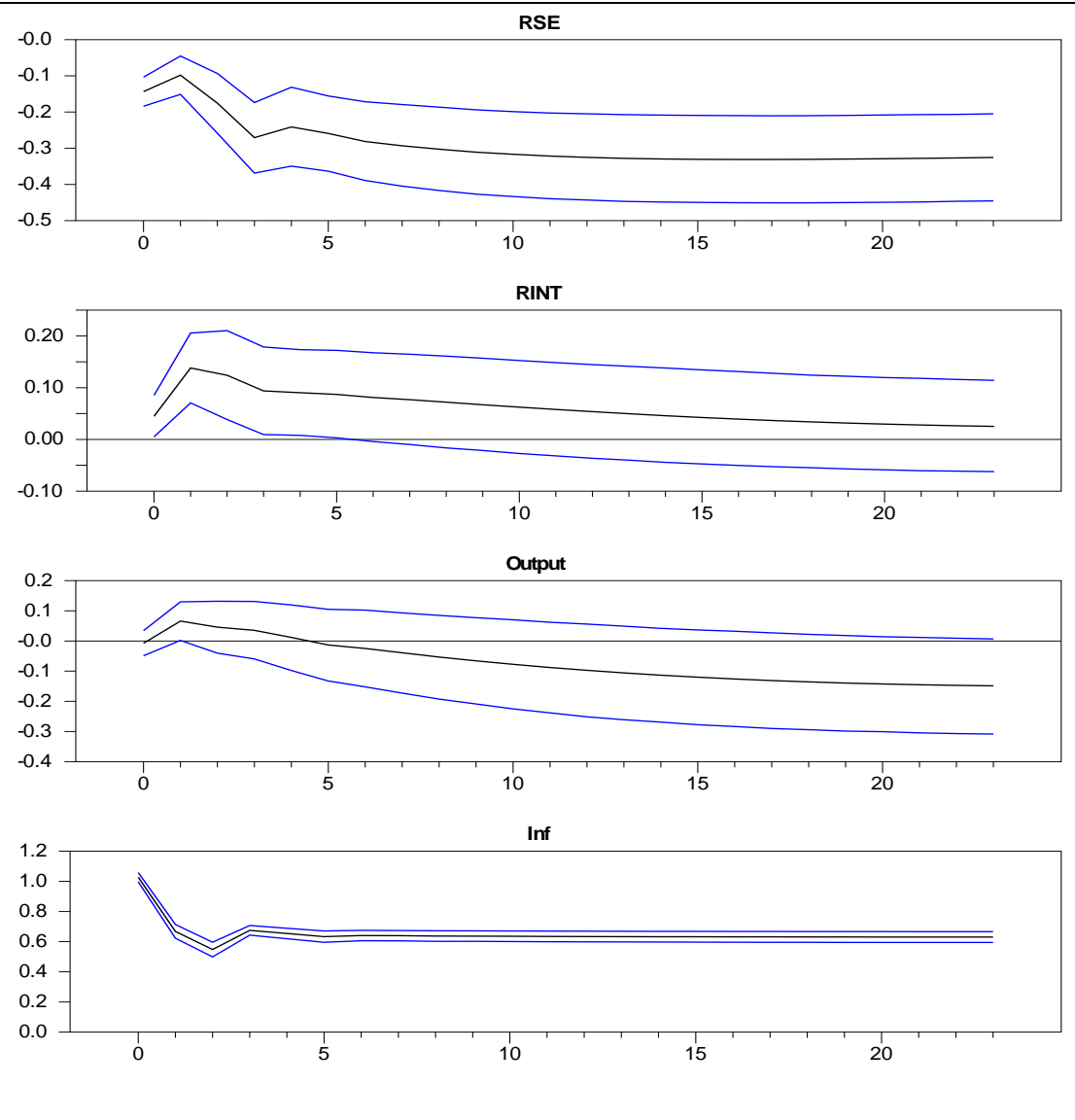


\section{Figure 5: Generalized Impulse Responses of Variables to Shocks to the Corresponding Factors}

Panel A: Responses to a Shock to the Equity Factor
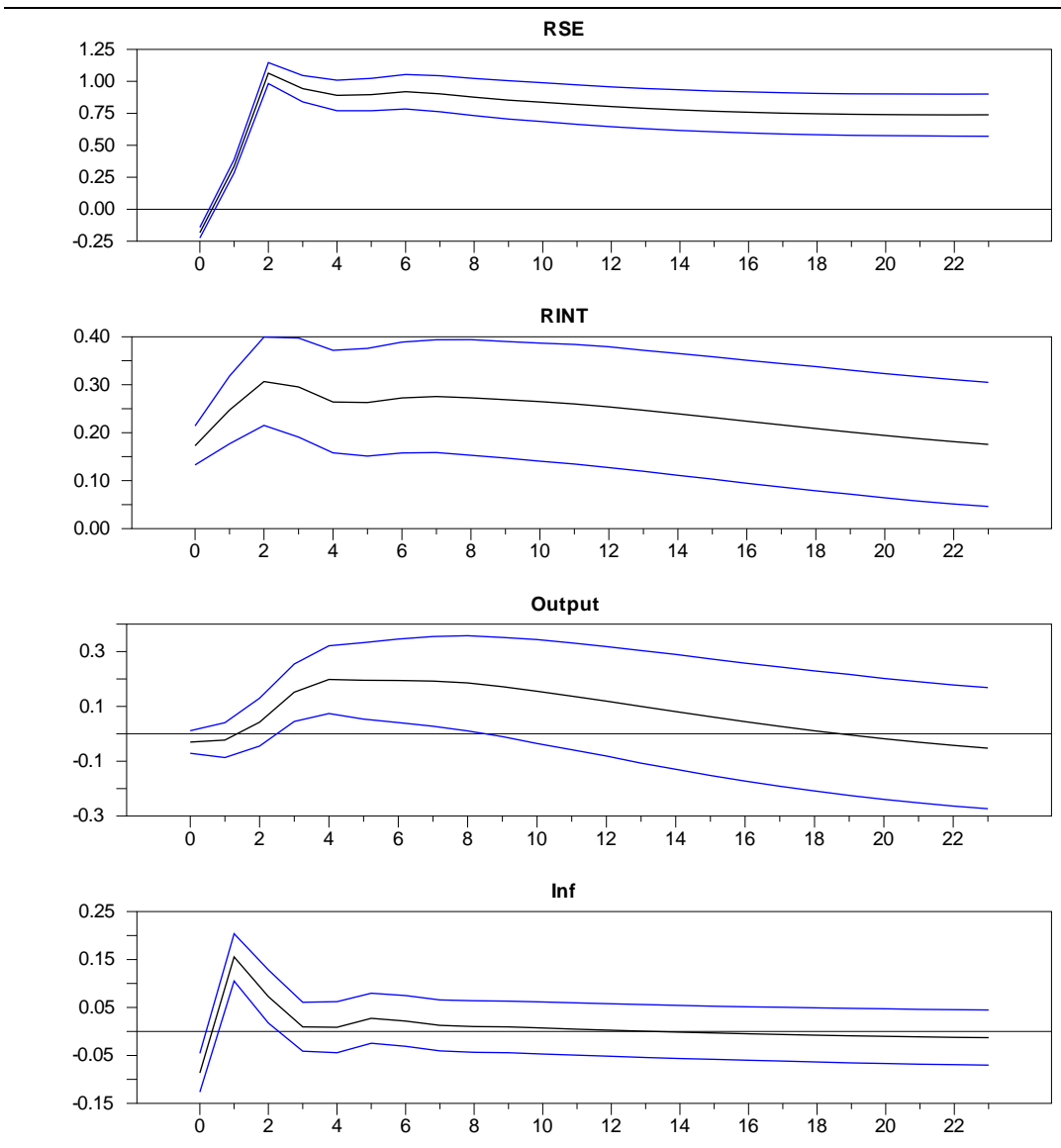

Panel B: Responses to a Shock to the Real Interest Rate Factor
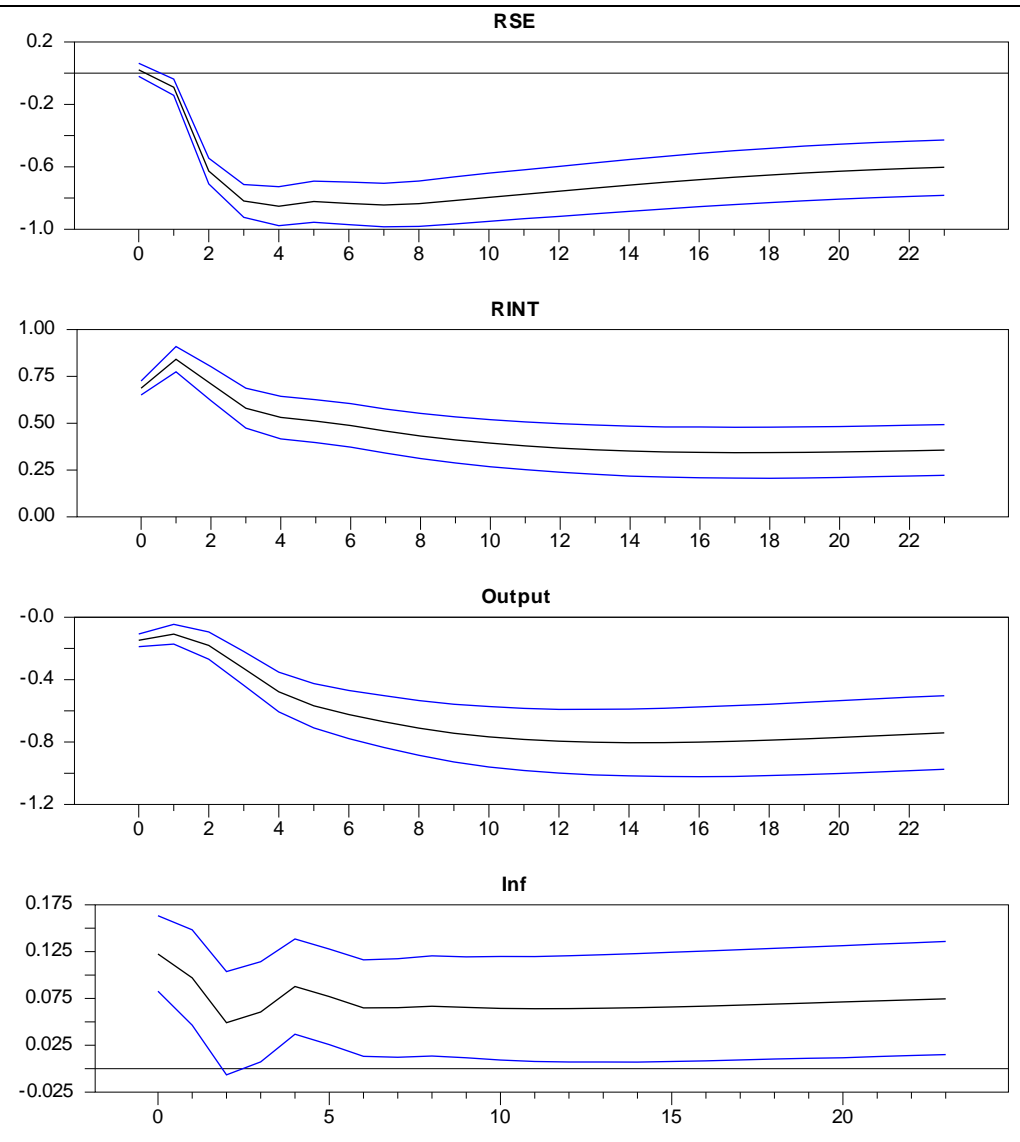


\section{Figure 6: Generalized Impulse Responses of Variables of Shocks to the Corresponding Factors}

Panel A: Responses to a Shock to the Real Economic Activity Factor
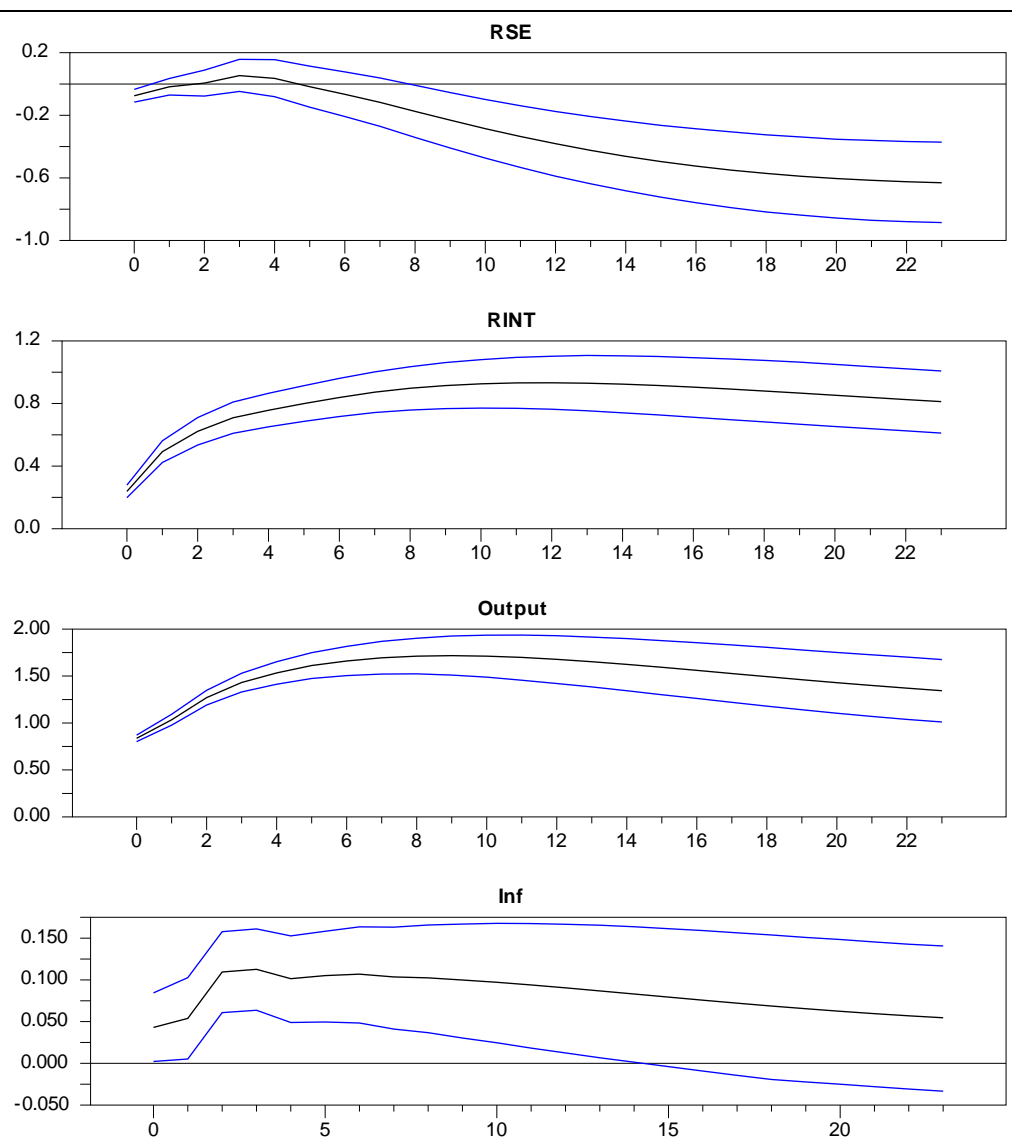

Panel B: Responses to a Shock to the Inflation Factor
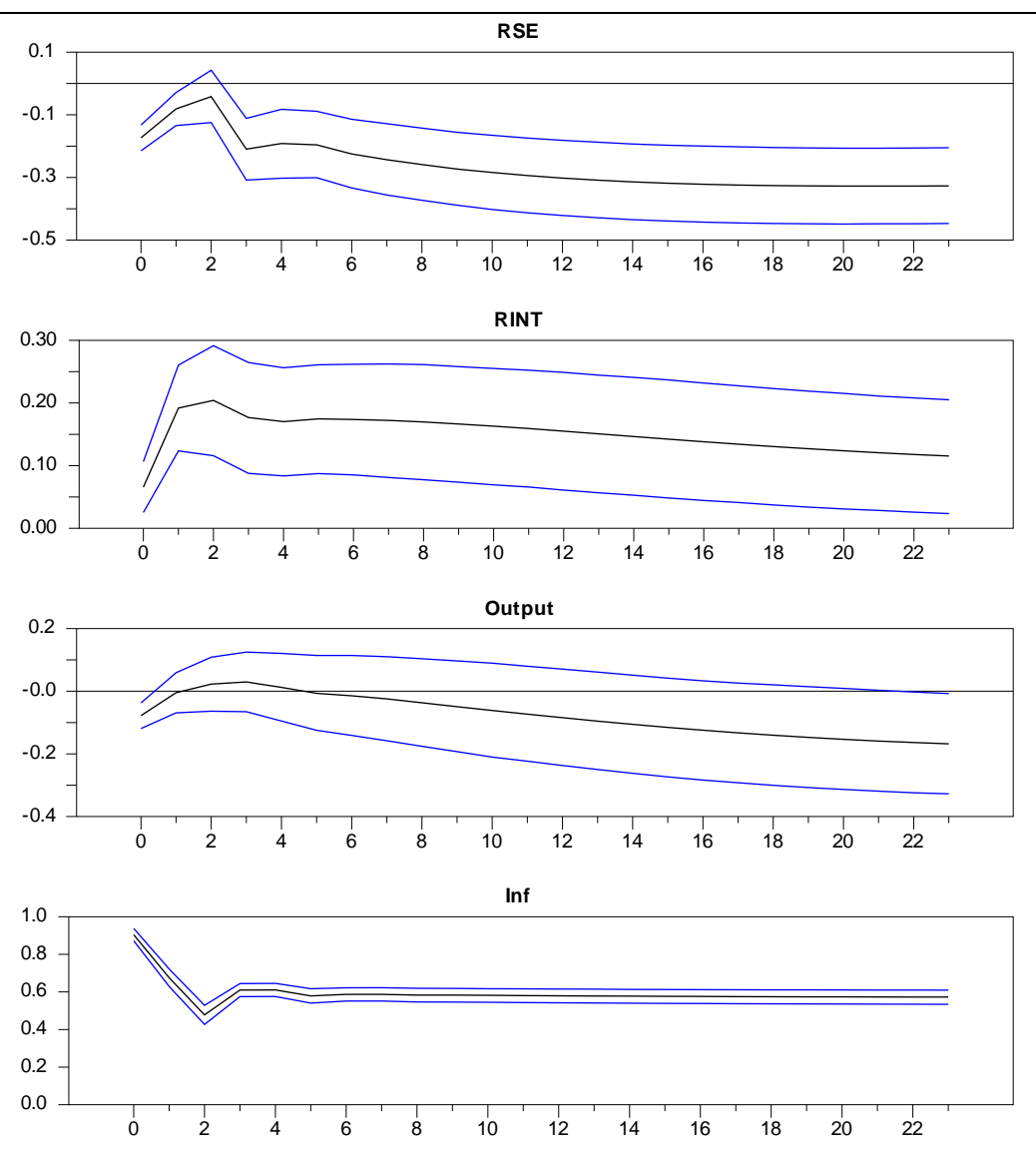


\section{Figure 7: Time-varying 12 month Accumulated Generalized Impulse Responses}

\begin{tabular}{l|l}
\hline Panel A: Time-varying Responses to a Real Stock Return Shock & Panel B: Time-varying Responses to a Real Interest Rate Shock
\end{tabular}
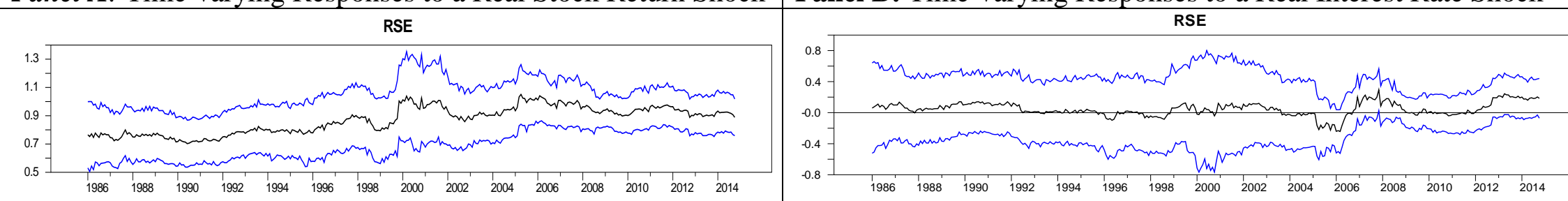

RINT
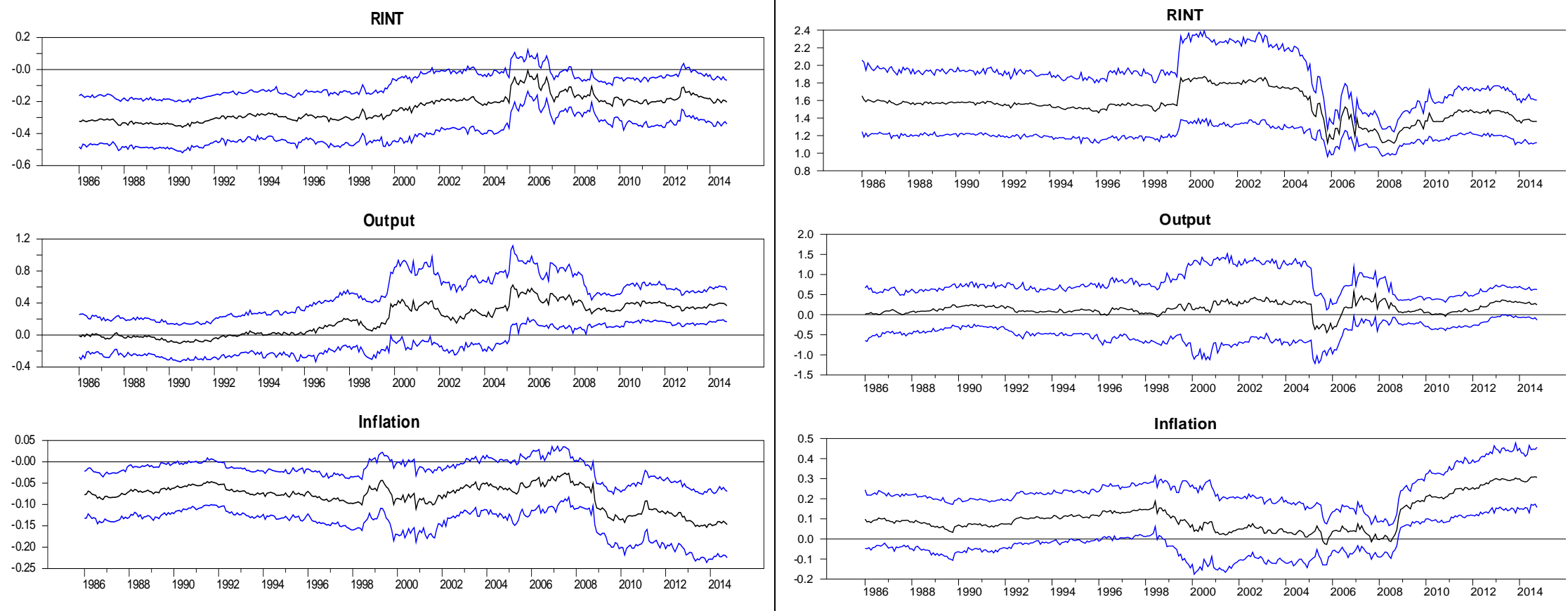


\section{Figure 8: Time-varying 12 month Accumulated Generalized Impulse Responses}

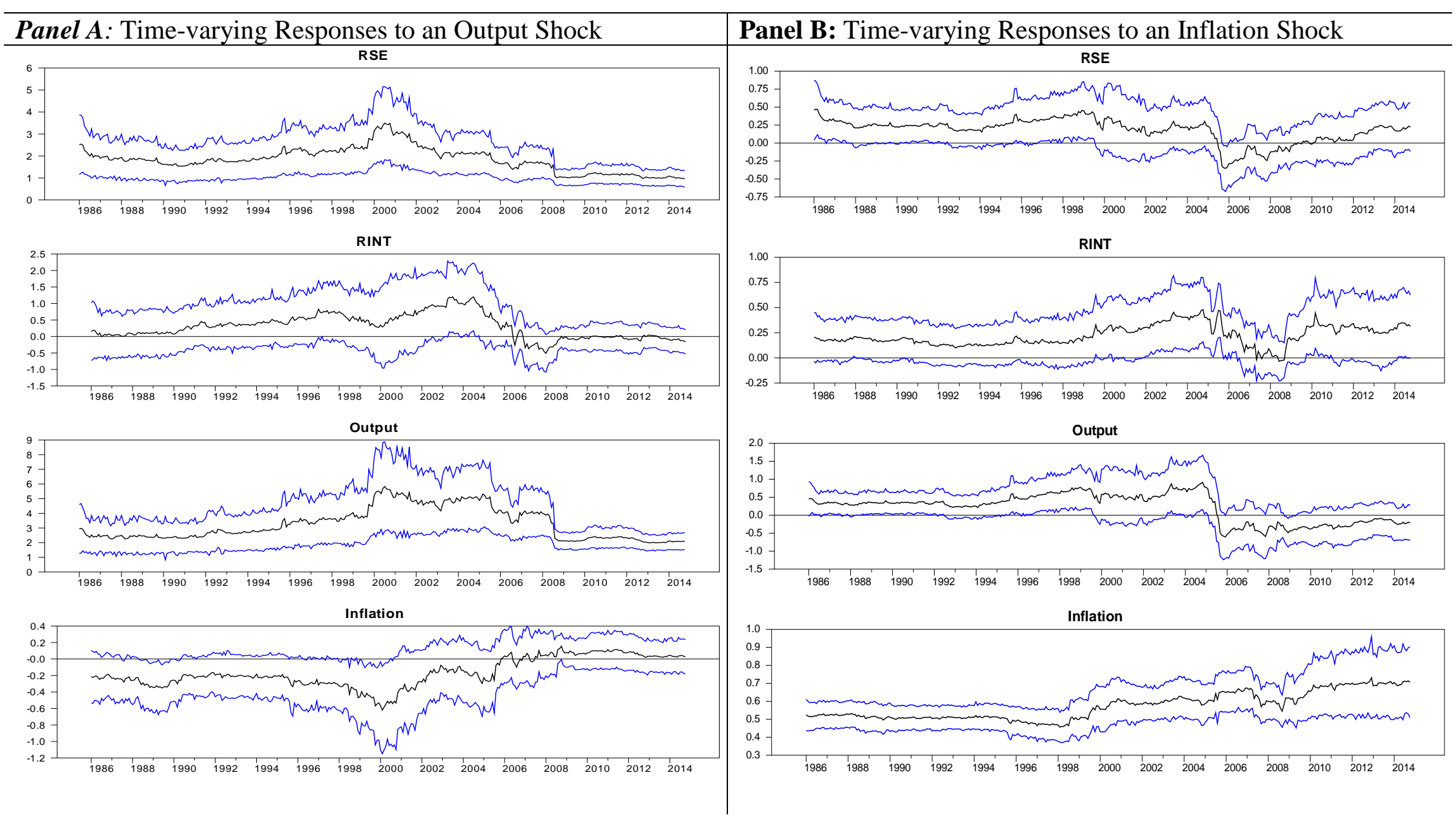




\section{Figure 9: Generalized Impulse Responses of Variables From Second FAVAR: Equation (14)}

Panel A: Generalized Impulse Responses: Shock to RSE
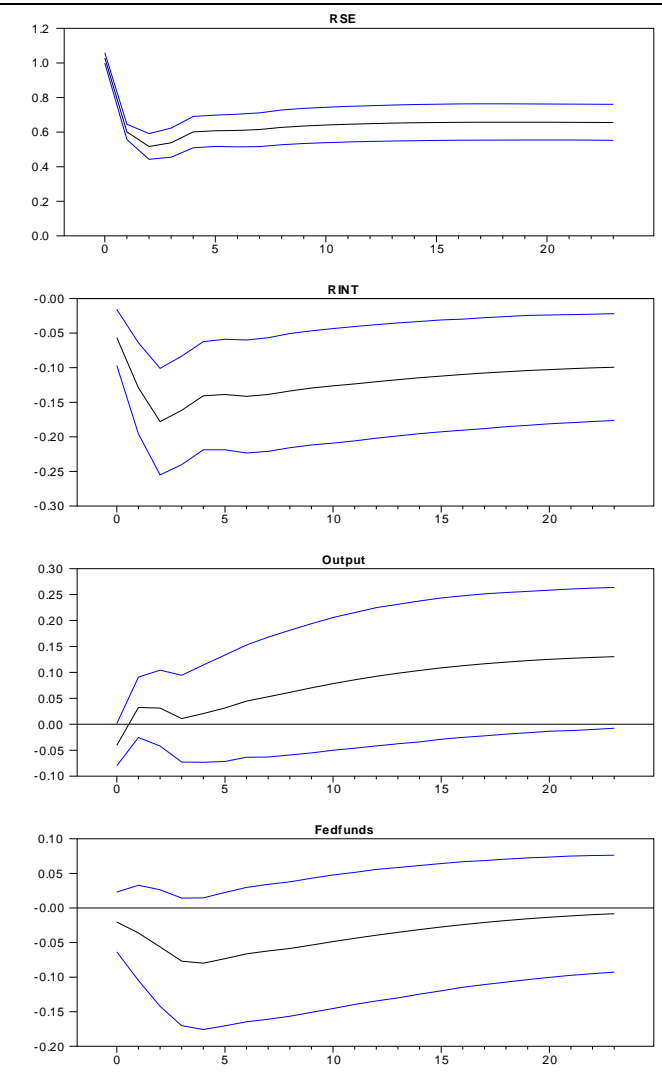

Intation

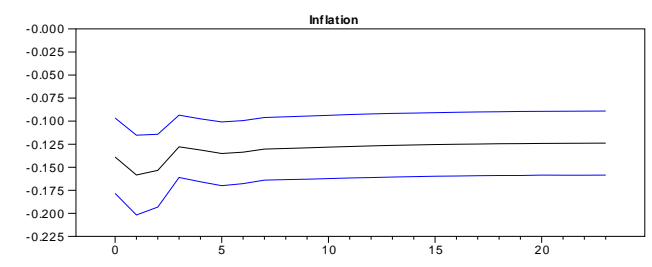

Panel B: Generalized Impulse Responses: Shock to Fedfunds
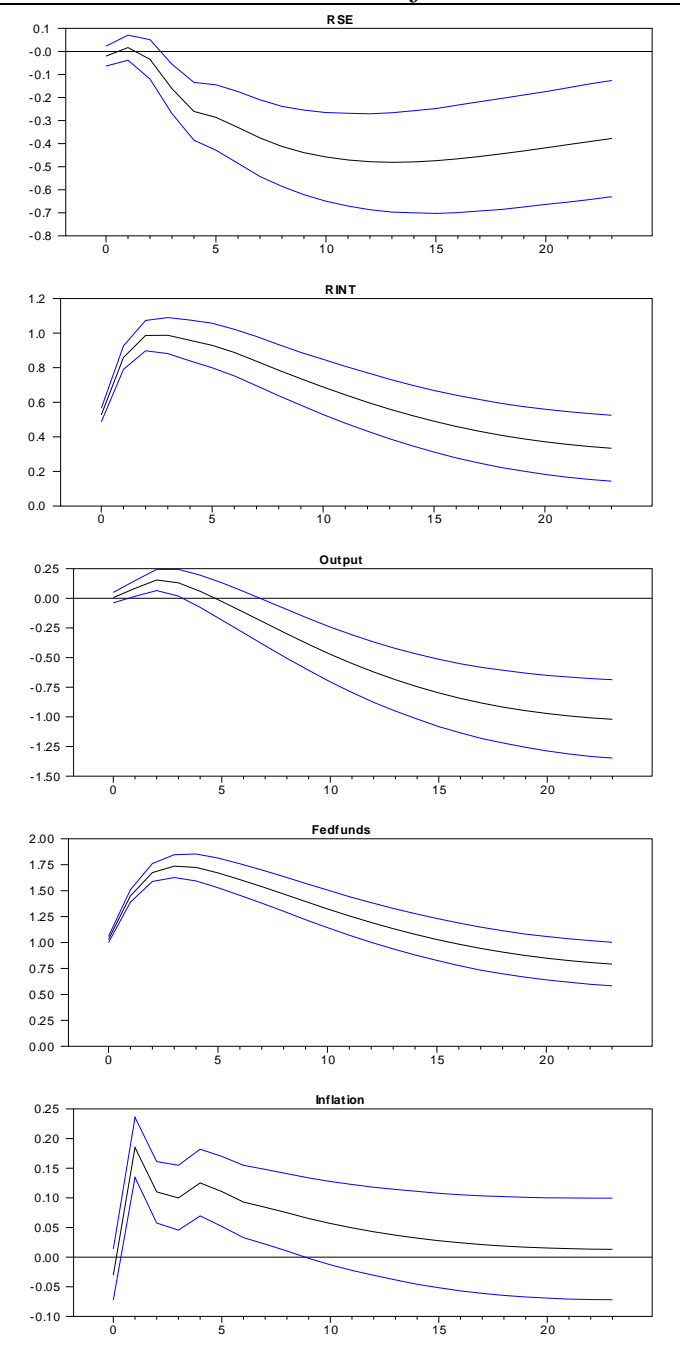

Panel C: Generalized Impulse Responses: Shock to Inflation
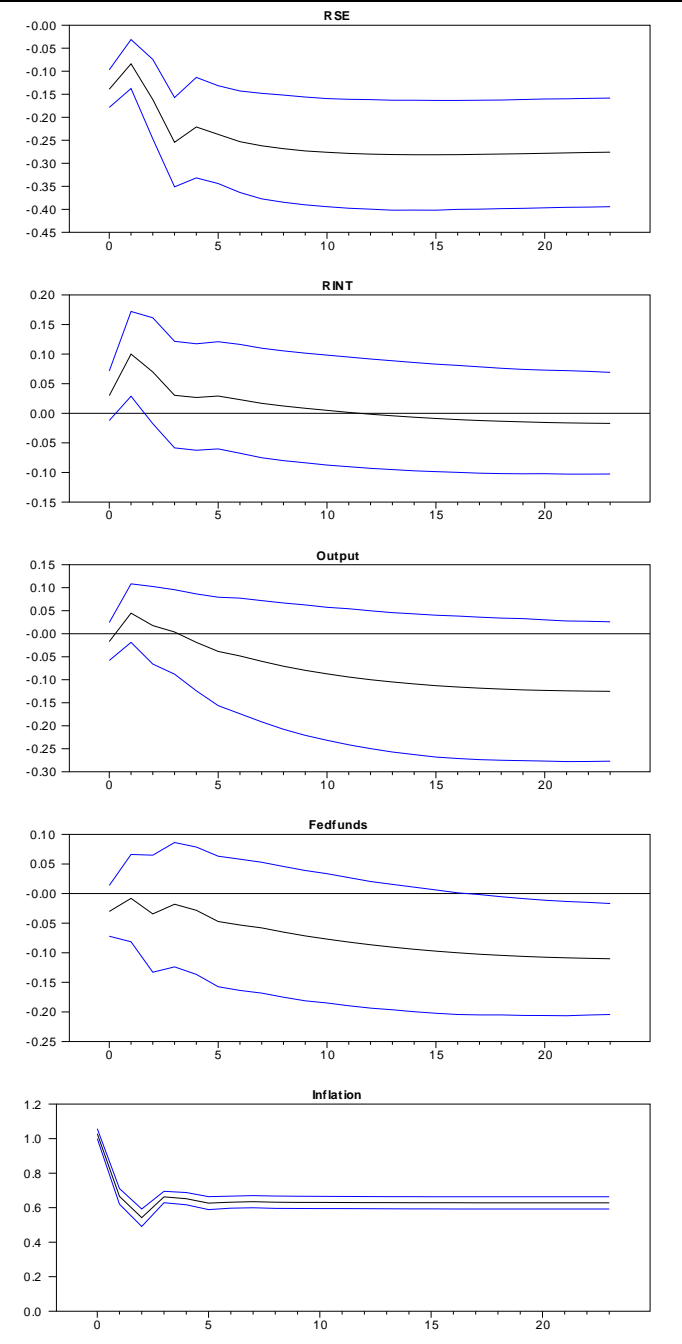
Variables Used From the McCracken and Ng (2014) Dataset

\begin{tabular}{|c|c|c|c|}
\hline Symbol & Description & Symbol & Description \\
\hline AAA & Aaa Corporate Bond Yield & IPMAT & IP: Materials \\
\hline AAAFFM & Aaa - FFR spread & IPNCONGD & IP: Nondurable Consumer Goods \\
\hline AMBSL & St. Louis Adjusted Monetary Base & IPNMAT & IP: Nondurable Materials \\
\hline AMDMNOX & Orders: Durable Goods & ISRATIOX & Inventories to Sales Ratio \\
\hline AMDMUOX & Unskilled Orders: Durable Goods & M1SL & M1 Money Stock \\
\hline AWHMAN & Hours: Manufacturing & M2REAL & Real M2 Money Stock \\
\hline AWOTMAN & Overtime Hours: Manufacturing & M2SL & M2 Money Stock \\
\hline BAA & Baa Corporate Bond Yield & MANEMP & All Employees: Manufacturing \\
\hline BAAFFM & Baa - FFR spread & MZMSL & MZM Money Stock \\
\hline BUSINVX & Total Business Inventories & NAPM & ISM: PMI Composite Index \\
\hline BUSLOANS & Commercial and Industrial Loans & NAPMEI & ISM Manufacturing: Employment \\
\hline CAPUTLB00004S & Capacity Utilization: Manufacturing & NAPMII & ISM: Inventories Index \\
\hline CE16OV & Civilian Employment & NAPMNOI & ISM: New Orders Index \\
\hline CES0600000007 & Hours: Goods-Producing & NAPMPI & ISM Manufacturing: Production \\
\hline CES068 & Ave. Hourly Earnings: Goods & NAPMPRI & ISM Manufacturing: Prices \\
\hline CES1021000001 & All Employees: Mining and Logging & NAPMSDI & ISM: Supplier Deliveries Index \\
\hline CES28 & Ave. Hourly Earnings: Construction & NDMANEMP & All Employees: Nondurable goods \\
\hline CES308 & $\begin{array}{l}\text { Ave. Hourly Earnings: } \\
\text { Manufacturing }\end{array}$ & NONBORRES & Nonborrowed Reserves \\
\hline CLAIMSX & Initial Claims & NONREVSL & Total Nonrevolving Credit \\
\hline CLF16OV & Civilian Labor Force & OILPRICE & Crude Oil Prices: WTI \\
\hline CMRMTSPLX & Real M\&T Sales & OUTPUT1 & Industrial Production: Bong Soo Lee (1992) \\
\hline COMPAPFF & CP - FFR spread & PAYEMS & All Employees: Total nonfarm \\
\hline CONSPI & Credit to PI ratio & PCEPI & PCE: Chain-type Price Index \\
\hline СР3M & 3-Month AA Comm. Paper Rate & PERMIT & Permits \\
\hline CPIAPPSL & CPI: Apparel & PERMITMW & Permits: Midwest \\
\hline CPIMEDSL & CPI: Medical Care & PERMITNE & Permits: Northeast \\
\hline CPITRNSL & CPI: Transportation & PERMITS & PERMITS \\
\hline CPIULFSL & CPI: All Items Less Food & PERMITW & Permits: West \\
\hline CUSR0000SA0L5 & CPI: All items less medical care & PPICMM & PPI: Commodities \\
\hline CUSR0000SAC & CPI: Commodities & PPICRM & PPI: Crude Materials \\
\hline CUSR0000SAS & CPI: Services & PPIFCG & PPI: Finished Consumer Goods \\
\hline CUUR0000SA0L2 & CPI: All items less shelter & PPIFGS & PPI: Finished Goods \\
\hline CUUR0000SAD & CPI: Durables & PPIITM & PPI: Intermediate Materials \\
\hline DD_1 & PCE: Durable goods & REALLN & Real Estate Loans \\
\hline $\mathrm{DD} \_2$ & PCE: Nondurable goods & RETAILX & Retail and Food Services Sales \\
\hline DD_3 & PCE: Services & RINT1 & Real Interest Rates: Bong Soo Lee (1992) \\
\hline DMANEMP & All Employees: Durable goods & RPI & Real Personal Income \\
\hline DPCERA & Real PCE & RSE1 & Real Stock Returns: Bong Soo Lee (1992) \\
\hline DTCOLNVHFNM & Consumer Motor Vehicle Loans & SP500 & Return on the S\&P 500 \\
\hline
\end{tabular}




\begin{tabular}{l|l|l|l}
\hline DTCTHFNM & Total Consumer Loans and Leases & SPDIV & S\&P div yield \\
\hline EXCAUS & Canada / U.S. FX Rate & SPINDUST & S\&P: Industrials \\
\hline EXJPUS & Japan / U.S. FX Rate & SPPE & S\&P: Price-Earnings Ratio \\
\hline EXSZUS & Switzerland / U.S. FX Rate & SRVPRD & All Employees: Service Industries \\
\hline EXUSUK & U.S. / U.K. FX Rate & T10YFFM & 10 yr. - FFR spread \\
\hline FEDFUNDS & FEDFUNDS & T1YFFM & 1 yr. - FFR spread \\
\hline GS1 & 1-Year T-bond & T5YFFM & 5 yr. - FFR spread \\
\hline GS10 & 10-Year T-bond & TB3SMFFM & 3 Mo. - FFR spread \\
\hline GS5 & 5-Year T-bond & TB6MS & 6-Month T-bill \\
\hline HOUST & Starts: Total & TB6SMFFM & 6 Mo. - FFR spread \\
\hline HOUSTMW & Starts: Midwest & TOTRESNS & Total Reserves \\
\hline HOUSTNE & Starts: Northeast & UEMP15OV & Civilians Unemployed $>15$ Weeks \\
\hline HOUSTS & Starts: South & UEMP15T26 & Civilians Unemployed 15-26 Weeks \\
\hline HOUSTW & Starts: West & UEMP27OV & Civilians Unemployed $>27$ Weeks \\
\hline INF1 & Inflation: Bong Soo Lee (1992) & UEMP5TO14 & Civilians Unemployed 5-14 Weeks \\
\hline INVEST & Securities in Bank Credit & UEMPLT5 & Civilians Unemployed <5 Weeks \\
\hline IPB51222S & IP: Residential Utilities & UEMPMEAN & Average Duration of Unemployment \\
\hline IPBUSEQ & IP: Business Equipment & UNRATE & Civilian Unemployment Rate \\
\hline IPCONGD & IP: Consumer Goods & USCONS & All Employees: Construction \\
\hline IPDCONGD & IP: Durable Consumer Goods & USFIRE & All Employees: Financial Activities \\
\hline IPDMAT & IP: Durable Materials & USGOOD & All Employees: Goods-Producing \\
\hline IPFINAL & IP: Final Products & USGOVT & All Employees: Government \\
\hline IPFPNSS & IP: Final Products and Supplies & USTPU & All Employees: TT\&U \\
\hline IPFUELS & IP: Fuels & USTRADE & All Employees: Retail Trade \\
\hline IPMANSICS & IP: Manufacturing & USWTRADE & All Employees: Wholesale Trade \\
\hline & & W875RX1 & RPI ex. Transfers \\
\hline & & &
\end{tabular}

